\title{
Corporate Hierarchies and the Size of Nations: Theory and Evidence*
}

\author{
Dalia Marin, University of Munich \\ Thierry Verdier, Paris School of Economics
}

First Version: April 2005

This Version: November 2006

\footnotetext{
*A previous version circulated under the title 'Corporate Hierarchies and International Trade'. Part of the paper was written when Dalia Marin visited the Stern School of Business of New York University. She thanks for the hospitality and stimulating discussions. We also would like to thank Denis Gromb, Irena Grosfeld, Elhanan Helpman, and Daniel Sturm for helpful comments and Thorsten Hansen and Alexander Raubold for excellent research assistance. The paper benefited from presentations at Conferences on Globalization and Contracts, Paris School of Economics, on Competition Policy for International Development, Growth and Trade, Brussels, on Governance and the Efficiency of Economic Systems, SFB-TR 15, Tutzing, at the NBER International Trade and Organization Working Group Meeting, Cambridge, at the CEPR European Research Workshop in International Trade (ERWIT 2006), Vienna and at the European Economic Association Congress EEA 2006, Vienna. Financial Support by the Volkswagen Foundation through the network grant 'Globalization and the Organization of Firms and Markets' and by the German Science Foundation through Sonderforschungsbereich GESY SFB/TR 15 and through DFG-Ma 1823/3-1 is gratefully acknowledged.
} 


\begin{abstract}
Corporate organization varies within a country and across countries with country size. The paper starts by establishing some facts about corporate organization based on unique data of 660 Austrian and German corporations. The larger country (Germany) has larger firms with flatter more decentral corporate hierarchies compared to the smaller country (Austria). Firms in the larger country change their organization less fast than firms in the smaller country. Over time firms have been introducing less hierarchical organizations by delegating power to lower levels of the corporation. We develop a theory which explains these facts and which links these features to the trade environment that countries and firms face. We introduce firms with internal hierarchies in a Krugman (1980) model of trade. We show that international trade and the toughness of competition in international markets induce a power struggle in firms which eventually leads to decentralized corporate hierarchies. We offer econometric evidence which is consistent with the models predictions.
\end{abstract}

JEL Classification: F12, F14, L22, D23

Keywords: international trade with endogenous firm organizations, trade and corporate organization in similar countries, power struggle in the firm, corporate organization in Austria and Germany, empirical test of the theory of the firm 


\section{Introduction}

Corporate organization varies within a country and across countries with country size. We establish some stylized facts about corporate organization for two countries which are similar in many dimensions like factor endowments, geography, institutions, culture, language, but market size. With a population of 8 million Austria is one tenth the size of Germany with a population of 82 million people. ${ }^{1}$ We document the pattern of corporate organization based on unique data of 460 German and 200 Austrian corporations in $1998-1999 .^{2}$

Corporate organization appears to vary with country size. The larger country (Germany) has firms with more decentral corporate decision making compared to the smaller country (Austria). Table 1 provides an illustration of this fact. In Austria, almost 40 percent of firms organize corporate decisions centrally at the top of the organization (at the CEO level) compared to 24.4 percent of German corporations. German corporations tend to have an internal power structure which is more cooperatively run between the CEO and the divisional level (50.4 percent of firms in Germany compared to 41.3 percent in Austria). Firms are ranked by their level of centralization over several corporate decisions. The numbers in Table 1 are averages over several corporate decisions ranging between 1 and 5 with 1 as central decision at the CEO level and 5 as decentral decision taken at the divisional level (see footnotes of Table 1 and the Data Appendix for a more detailed description).

\footnotetext{
${ }^{1}$ In 1998 Austria had an export ratio of 44.9 percent of GDP and Germany of 28.7 percent.

${ }^{2}$ For more details on the data see the Appendix and Marin (2006).
} 
Table 1 Power Distribution among Corporations ${ }^{1)}$

\begin{tabular}{lcc} 
& Austria & Germany \\
& \multicolumn{2}{c}{ corporate decisions $^{2)}$} \\
level of centralization $^{3)}$ & \multicolumn{2}{c}{ in percent of all firms $^{2}$} \\
\hline $1.00-2.50$ & 39.2 & 24.3 \\
$2.51-3.50$ & 41.3 & 50.4 \\
$3.51-5.00$ & 19.6 & 25.2 \\
\hline
\end{tabular}

\footnotetext{
Source: Chair of International Economics, University of Munich, firm survey of 660 German and Austrian firms

1) The F-statistics $=8.67$ rejects the null of no difference in the power distribution among firms in Austria and Germany at the 0.004 significance level.

${ }^{2)}$ Corporate decisions include: decision over acquisitions, financial decisions, new strategy, finding acquisitions, transfer prices, introduction of new products, R\&D expenditures, budget, hiring more than $10 \%$ of current personnel, hiring two workers, change of supplier, price increase of product, decision over product price, moderate wage increase, firing of personnel, hiring a secretary

${ }^{3)}$ Level of centralization: corporate decisions are ranked between 1 and 5 with 1 as the decision taken by the CEO at the top of the headquarter and 5 as the decision taken at the divisional level. Firms are ranked by their level of centralization in decision making over 16 decisions (Germany) and 13 decisions (Austria), respectively. The numbers are averages over the 16 decisions ( 13 decisions) undertaken by firms. A firm with a mean of 1 is centralized and a firm with a mean of 5 is decentralized. For the ranking of each of these corporate decisions see Appendix.
}

Figure 1 and Table 3 illustrate a second fact about corporate organization across firms within a country. The allocation of power inside the corporation appears to vary with firm size. Larger firms tend to have a more decentral power structure compared to smaller firms. Furthermore, the type of organization differs in a cross section of firms with around a quarter of firms opting for the central U-form organization and around 20 percent installing the decentral M-form organization (Table 3).

Figure 1 Level of Centralization and Firm Size
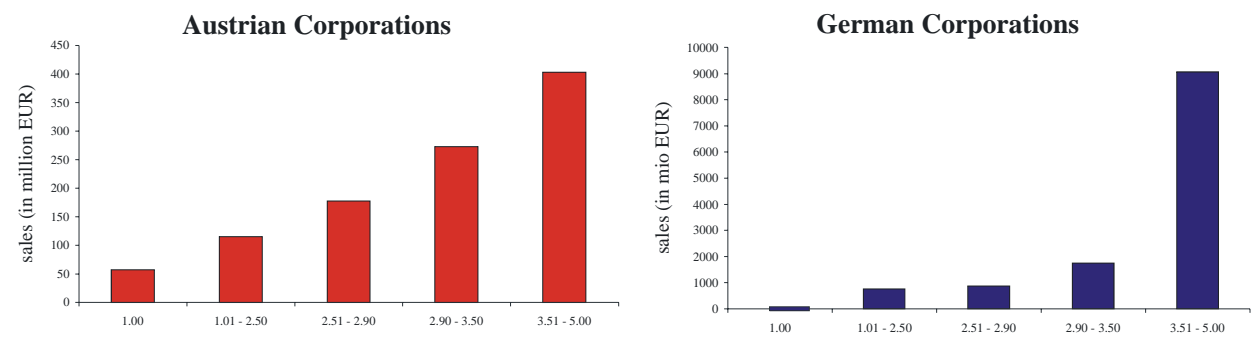

horizontal axis: level of centralization of corporate decisions, see footnotes 2 and 3 of Table 1 for defintion. 
Table 2 unveils a third pattern of the data. Organizational change appears to vary with country size. Firms in the smaller more open economy change their organization faster than firms in the larger less open country. In Austria, the share of firms with a new organization (less than two years of age) is almost twice as large compared to Germany.

Table $2 \quad$ Age of Organization in Corporations

\begin{tabular}{lcc}
\hline & Austria & Germany \\
\hline less than two years & 26.2 & 15.6 \\
two to eight years & 21.4 & 27.1 \\
nine to fifteen years & 14.1 & 23.7 \\
more than fifteen years & 38.3 & 33.5 \\
$\quad$ of which unchanged since foundation & 30.6 & 16.9 \\
\hline Source: Chair of International Economics, University of Munich, firm survey of 660 German and Austrian firms
\end{tabular}

Source: Chair of International Economics, University of Munich, firm survey of 660 German and Austrian firms

Table 3 illustrates the fourth fact. Over time, firms have been introducing less hierarchical organizations by delegating power to lower levels of the corporation. In 1999, 26.5 percent of German firms use the centralized U-form organization compared to 45.5 percent before. Table 3 shows a gradual decline since 1989 (over the last 10 years) in the importance of the U-form organization in which power is concentrated at the top of the corporate hierarchy. Firms have been shifting towards the decentralized M-form organization which introduces profit centers at the divisional level providing incentives for workers at lower levels of the corporate hierarchy. The importance of the M-form organization increased from 10.5 percent of firms using it before to 20.5 percent adopting it in 1999. A similar more pronounced trend towards less hierarchical organizations can be found for Austria. ${ }^{3} 4$

\footnotetext{
${ }^{3}$ For the distinction between the M- and the U-form organization see Williamson (1975).

${ }^{4}$ Empirical evidence on the changing nature of corporate hierarchies is scarce. Besides anecdotal evidence in the business press there are a few studies which document these corporate changes for US corporations see Ostermann (1996), Holmstrom and Kaplan (2001), Rajan and Wulf (2003).
} 


\begin{tabular}{|c|c|c|c|c|c|c|c|c|}
\hline \multirow[t]{4}{*}{ Table 3} & \multicolumn{8}{|c|}{ Organizational Change } \\
\hline & \multicolumn{8}{|c|}{ in percent of all firms with a change in organization ${ }^{1)}$} \\
\hline & \multicolumn{4}{|c|}{ Austrian Corporations } & \multicolumn{4}{|c|}{ German Corporations } \\
\hline & today & before & $\begin{array}{l}5 \text { years } \\
\text { before }\end{array}$ & $\begin{array}{l}10 \text { years } \\
\text { before }\end{array}$ & today & before & $\begin{array}{l}5 \text { years } \\
\text { before }\end{array}$ & $\begin{array}{l}10 \text { years } \\
\text { before }\end{array}$ \\
\hline functional (U-form) & 24.2 & 51.1 & 34.5 & 43.2 & 26.5 & 45.5 & 33.5 & 40.4 \\
\hline holding (H-form) & 31.6 & 11.9 & 23.7 & 16.4 & 25.5 & 7.5 & 19.4 & 14.1 \\
\hline multidivisional & 5.8 & 11.9 & 10.1 & 10.3 & 12.5 & 17.2 & 13.5 & 14.7 \\
\hline $\begin{array}{l}\text { divisional with groups } \\
\text { and/or sectors (M-form) }\end{array}$ & 19.7 & 6.7 & 10.1 & 9.6 & 20.5 & 10.4 & 20.0 & 18.6 \\
\hline $\begin{array}{l}\text { divisional with functions } \\
\text { (MU-form) }\end{array}$ & 19.0 & 12.6 & 19.6 & 15.8 & 15.0 & 18.7 & 13.5 & 12.2 \\
\hline other & - & 5.9 & 2.0 & 4.8 & - & 0.7 & - & - \\
\hline
\end{tabular}

Source: Chair of International Economics. University of Munich, firm survey of 660 German and Austrian firms

1) In Germany 58.1 percent of firms reported a change in organization and in Austria 86.3 percent of firms.

The described features raise several questions. First, can differences in countries' trade exposure account for the observed corporate diversity across countries and firms? Second, why are firms changing their mode of organization? Can an increased integration into world markets explain this trend towards less hierarchical organizations?

In this paper we offer a model that explains these stylized facts. We introduce firms with internal hierarchies (a CEO and a division manager) in a Krugman (1980) model of trade under monopolistic competition. Our model simultaneously determines firms' organizational choices and heterogeneity across firms in size and productivity. Moreover, in our model firms choose their organization in response to the trade environment they face.

We develop a general equilibrium model with a monopolistic competitive sector with differentiated goods that combines the Aghion-Tirole (1997) (AT) theory of the firm with the Krugman (1980) theory of international trade. Rather than using constant elasticity of substitution (CES) utility as in Krugman (1980), we adopt the Melitz and Ottaviano (2003) framework with linear demand across a continuum of varieties. This way the price elasticity of demand is no longer exogenously fixed and changes with the thoughness of competition in the market. Consumers have preferences over varieties. Production of the varieties in the monopolistic sector is as in AT. A principal hires an agent to monitor projects and workers to produce. There are $m$ potential methods of production of which one maximizes profits and another one maximizes a private benefit for the agent. Hence, there is a conflict of interest between the principal/owner and her agent as the payoffs 
of the parties depend on who's project is implemented. The principal and the agent gather information which of the $m$ ways to run the firm maximizes profits and the private benefit of the agent, respectively. If both parties find out which are their preferred projects, the decision rights reside in the party with formal power. If only one of the parties learns which her preferred project is, the uninformed party always rubber-stamps this project. In this case, the informed party has real power. In choosing between keeping formal power or delegating power to the agent, the principal trades off the benefit from control against the manager's loss of initiative.

The first result of the paper states that the conflict of interest between the principal and her agent (the power struggle in the firm) increases with the intensity of competition in the market. When competition becomes tougher (with an increase in the number of firms and/or with an increase in the share of low cost firms in the market) relative profits decline between a firm in which the agent has power (an A-firm) and a firm in which the principal decides over the project (a P-firm). Hence, it becomes more costly to delegate power to the agent. It matters more who runs the firm, because as competition increases high-cost A-firms' revenues go down by more than those of lowcost P-firms and they try to fight the loss in revenues by lowering mark-ups by more than P-firms.

We then solve for the industry equilibrium (imposing free entry and factor market clearing). We find that the power struggle in firms increases the stakes of firms and thus increases the free entry profit level that firms require to enter the market. We find further, that the power struggle in firms affects the corporate equilibrium that emerges in the economy. When the conflict of interest between the principal and her agent is small, preferences over projects between the principal and her agent are fairly congruent and the principal invests little in information collection. Under these circumstances the initiative of the agent can be kept alive and there are no costs of control. Hence, principals find it optimal to keep control. On the other hand, when the conflict of interest is large, the principal's investment in information collection will also tend to be large, and the agent's initiative will be killed even when he is given formal power. Hence, there is no gain in assigning formal power to the agent and principals keep control. Finally, there may exist intermediate levels of conflict in the firm for which principals find it optimal to delegate formal power to their agents to induce them to invest in information collection.

Next, we open the economy up to trade by examining changes in market size. Interestingly, we find that the size of nations is an important determi- 
nant of the equilibrium mode of organization. In small countries (with little $L$ ), competition tends to be weak and the conflict of interest between principals and managers will also tend to be small and principals tend to monitor little. On the other hand, in large countries (with large $L$ ), competition and the power struggle in firms are both intense and principals tend to monitor a lot. It follows that small and large countries will tend to have firms in which principals keep formal control, while in medium sized countries firm organizations may prevail in which power is delegated to the manager.

Finally, we derive predictions from our model and expose them to an econometric test. We predict that in a cross section of countries and firms, larger countries will have tougher competition with larger more decentral corporate hierarchies compared to smaller countries. We predict further, that in a cross section of countries and firms, firms in larger countries more exposed to competition will experience more intense power struggles inside corporations. We test these predictions for a cross section of firms with unique data of 660 corporations in Austria and Germany in 1998-1999. We find that these predictions are not rejected by the data.

Our model builds on a new body of literature on organizations in general equilibrium models of international trade. ${ }^{5}$ We combine Krugman (1980) and Melitz and Ottaviano (2003) with Aghion and Tirole (1997). This allows us to study how international trade and the size of nations affect corporate organization in similar countries. The paper contributes in several respects to this literature. In their theory of the firm Aghion and Tirole (1997) assume an exogenous degree of conflict in the firm. We endogenize the power struggle inside firms by the trade environment firms face. Trade liberalization increases the costs of delegating power to the manager, since it matters more for profits who runs the firm. In earlier work (Marin and Verdier (2007)) we introduce firms' organizational choices in a Dixit and Stiglitz model of monopolistic competition. However, in this model market size and trade have no effect on corporate organization. As is typical for a model of monopolistic competition of the Dixit and Stiglitz (1977) type an increase in market size leads to an increase in the number of varieties produced without affecting the size of firms, markups and firm organization. In this paper we incorporate endogenous markups using the linear demand system as in Melitz and Ottaviano (2003). Markups across firms respond now to the toughness of competition in a market. This way our model exhibits a link between trade liberalization, firm size and the mode of organizations firms choose.

\footnotetext{
${ }^{5}$ For an overview of this literature, see Helpman (2006), Marin and Verdier (2003a), and Spencer (2005) .
} 
In contrast to the present paper, we examine in Marin and Verdier (2003b) how trade between dissimilar countries is affecting the corporate equilibrium organization of the world economy. We introduce organizational choices in a 2x2x2 Helpman and Krugman model of international trade in which countries differ in factor endowments. We find that relative factor endowments are important determinants of the equilibrium mode of organization. In countries where skilled labor is relatively scarce, the wage of unskilled workers will tend to be low, while the fixed costs of production (which consist of the wage of the skilled manager) will tend to be high, thus making entry more costly. As a result, the ratio of profits to the skilled wage is high in skill-scarce countries and low in skill-abundant countries. Hence, countries with high and low ratios of skilled workers to unskilled workers will tend to have firms in which principals keep formal power, while in countries with intermediate levels of relative skills power is delegated to skilled managers. We find further that when two countries with different relative factor endowments open up to trade, their factor prices will tend to converge and this could induce a convergence in corporate cultures leading all principals in both countries to delegate power (even when no principal in any of the two countries was delegating in autarky). Surprisingly, as in MV (2003b) with North-South trade between dissimilar countries, we find in the present paper that managers empowerment and the move to flatter corporate hierarchies emerge as an equilibrium when the world economy is governed by North-North trade as well.

The paper is organized in the following sections. Section 2 describes the closed economy version of the model and studies the optimal choice of firm organization. Section 3 derives the power struggle in firms as a function of the thoughness of competition in the market. The section then discusses the industry equilibrium with free entry and derives the interaction between the power struggle in firms and the equilibrium mode of organization. Section 4 opens the economy up to trade and studies the role of the size of nations in determining the corporate equilibrium. Section 5 presents econometric evidence supporting the view that trade and competition are explaining the allocation of power in firms as well as the conflict of interests between principals/owners and managers. Section 6 concludes. The proof of the main results and the description of the data are relegated to the Appendix. 


\section{The closed economy}

\subsection{Demand}

Consider an economy with $L$ consumers. Consumer preferences are defined over a continuum of differentiated varieties indexed by $i \in \Omega$ and a homogenous good chosen as the numeraire. They are given by

$$
U=q_{0}+\beta \int_{i \in \Omega} q_{i} d i-\frac{1}{2} \gamma \int_{i \in \Omega} q_{i}^{2} d i-\frac{1}{2} \eta\left[\int_{i \in \Omega} q_{i} d i\right]^{2}
$$

where $q_{0}$ and $q_{i}$ are respectively consumption of the numeraire good and of variety $i$ of the differentiated good. The demand parameters $\beta, \gamma$ and $\eta$ are positive with $\beta$ and $\eta$ giving the substitution between the differentiated varieties and the numeraire good and $\gamma$ as the degree of product differentiation between varieties $i$. When $\gamma=0$, varieties are perfect substitutes and consumers care only about the total consumption level over all varieties given by

$$
Q^{c}=\int_{i \in \Omega} q_{i} d i
$$

Let $p_{i}$ be the price of variety $i$. We assume that consumers have positive demand for the numeraire good. Then standard utility maximization gives the individual inverse demand function

$$
p_{i}=\beta-\gamma q_{i}-\eta Q^{c}
$$

whenever $q_{i}>0$. This will be the case when

$$
p_{i} \leq \frac{1}{\gamma+\eta N}(\gamma \beta+\eta N \bar{p})
$$

where $N$ is the measure of the set of varieties $\Omega$ with positive demand and $\bar{p}$ the average price index given by

$$
\bar{p}=\frac{1}{N} \int_{i \in \Omega} p_{i} d i
$$

It follows that

$$
\bar{p}=\beta-\frac{\gamma}{N} Q^{c}-\eta Q^{c}=\beta-\frac{\gamma+N \eta}{N} Q^{c}
$$

Total demand for variety $i$ can be expressed as

$$
q_{i}=L q_{i}=\frac{\beta L}{\gamma+N \eta}-\frac{L}{\gamma} p_{i}+\frac{N \eta}{\gamma+N \eta} \frac{L}{\gamma} \bar{p}
$$


where $q_{i}$ is the market demand for variety $i$ Note that in this linear demand system for varieties, the price elasticity of demand is driven by the 'toughness' of competition in the market induced either by a lower average price for varieties $\bar{p}$ or more product varieties $N$. The price elasticity of demand increases with lower $\bar{p}$ and larger $N$.

\subsubsection{Production}

The numeraire good 0 is produced with constant returns to scale (one unit of good 0 requires one unit of labor) under perfect competitive conditions. Each variety of the differentiated good is produced under monopolistically competitive conditions. Suppose that a given variety $i$ is produced with marginal $\operatorname{cost} c_{i}$, then profits for that variety can be written as

$$
\pi_{i}=q_{i}\left(p_{i}-c_{i}\right)
$$

The profit maximizing output level $q_{i}=q\left(c_{i}\right)$ and price level $p_{i}=p\left(c_{i}\right)$ are related to each other by:

$$
q_{i}=q\left(c_{i}\right)=\frac{L}{\gamma}\left[p\left(c_{i}\right)-c_{i}\right]
$$

or

$$
\frac{\beta}{\gamma+N \eta}-\frac{1}{\gamma} p\left(c_{i}\right)+\frac{N \eta}{\gamma+N \eta} \frac{1}{\gamma} \bar{p}=\frac{1}{\gamma}\left[p\left(c_{i}\right)-c_{i}\right]
$$

Note, that output per firm increases with the size of the market $L{ }^{6}$

The profit maximizing price can be written as

$$
p\left(c_{i}\right)=\frac{1}{2}\left[c_{i}+\frac{\beta \gamma}{\gamma+N \eta}+\frac{N \eta}{\gamma+N \eta} \bar{p}\right]
$$

with the (absolute) markup over price as

$$
m\left(c_{i}\right)=p\left(c_{i}\right)-c_{i}=\frac{1}{2}\left[\frac{\beta \gamma}{\gamma+N \eta}+\frac{N \eta}{\gamma+N \eta} \bar{p}-c_{i}\right]
$$

Note, that in addition to the taste for variety parameter $\gamma$ the markup is now also determined by the toughness of competition in the market induced

\footnotetext{
${ }^{6}$ In the the Dixit and Stiglitz (DS) model output per firm does not depend on market size. In the DS model a larger market increases the number of varities without changing firm size.
} 
either by a lower average price for varieties $\bar{p}$ or a larger number of varieties $N .^{7}$

The average price $\bar{p}$ and average cost of firms $\bar{c}$ can be expressed as

$$
\begin{gathered}
\bar{p}=\frac{\bar{c}+\frac{\beta \gamma}{\gamma+N \eta}}{\frac{2 \gamma+N \eta}{\gamma+N \eta}} \\
\bar{c}=\frac{1}{N} \int_{i \in \Omega} c_{i} d i
\end{gathered}
$$

Substituting (5) into (4) gives an expression for the markup $m\left(c_{i}\right)$ :

$$
m\left(c_{i}\right)=\frac{1}{2}\left[\frac{2 \beta \gamma}{2 \gamma+N \eta}+\frac{N \eta}{2 \gamma+N \eta} \bar{c}-c_{i}\right]
$$

and for profits

$$
\pi\left(c_{i}\right)=\frac{L}{4 \gamma}\left[\frac{2 \beta \gamma}{2 \gamma+N \eta}+\frac{N \eta}{2 \gamma+N \eta} \bar{c}-c_{i}\right]^{2}
$$

Free entry into the industry ensures zero expected profits for a potential entrant. Denote the cutoff cost level $c_{D}$ as

$$
c_{D}=\frac{2 \beta \gamma}{2 \gamma+N \eta}+\frac{N \eta}{2 \gamma+N \eta} \bar{c}
$$

which is the cost level of a firm who is indifferent between remaining or leaving the industry. This firm earns zero profits as its price is driven down to its marginal costs, $p\left(c_{D}\right)=c_{D}$. Firms with cost $c_{i}<c_{D}$ earn positive profits. The cut off cost level $c_{D}$ captures the 'toughness' of competition in an industry. The cut off cost level $c_{D}$ declines and competition is tougher with more firms around (with larger $N$ ), with more low cost firms in the market (with lower $\bar{c}$ ), and when varieties are closer substitutes (with smaller $\gamma$ ).

\subsubsection{Power in the Firm}

In this section, we determine the optimal choice of firm organization. We consider a firm with a simple hierarchy consisting of a CEO (the principal P) hiring a division manager (the agent $\mathrm{A}$ ) to implement a project. There are ex ante $m$ potential and a priori identical projects (or ways to produce a good).

\footnotetext{
${ }^{7}$ This stands in contrast to CES utility used in the DS model in which markups are fixed and exclusively determined by the taste for variety parameter $\gamma$.
} 
Payoffs are ex ante unknown to both parties. To make things interesting we assume that there is a conflict of interest between the principal and the agent. Among the $m$ projects, there is one which yields the highest possible benefit $B$ for the principal and one which yields the highest possible benefit $b$ for the agent. ${ }^{8}$ Let $\alpha B$ be the principal's expected benefit when the agent's best project is implemented with $(0 \leq \alpha \leq 1)$. We assume, for simplicity, that the agent's expected benefit when the principal's best project is implemented is $0 .{ }^{9} \alpha$ is a congruence parameter capturing the degree of conflict between the principal and her agent. The lower $\alpha$, the more is the principal's payoff reduced when the agent's best project is implemented and hence the larger the conflict of interest between the principal and her agent.

We turn now to the distinction between "formal" and "real power" in the firm. $B$ and $b$ are supposed to be known ex ante though the parties do not know ex ante which project yields such payoff. We assume also that, among the $m$ projects, there are some with very high negative payoffs to both parties, implying that choosing randomly a project without being informed is not profitable to both agents who instead prefer to do nothing (project 0 ). This aspect, together with the fact that each uninformed party prefers to rubber-stamp the other informed's party suggestion to do nothing, implies that private information about payoffs gives decision control to the informed party. In this case, the informed party has "real power" in the firm. There are two sources of power in the firm. "Formal power" which is allocated to the manager by contract and "real power" which parties may obtain by being better informed.

Both parties may acquire information on possible ways to run the firm. However, we assume that the CEO has managerial overload. By spending some resource costs the principal learns the payoffs of all projects with probability $E$ and remains uninformed with probability $1-E$. This generates costs of information collection of $g_{P}(E)=g \frac{E^{2}}{2}$. Similarly, by exerting some effort $g_{A}(e)=k e$ with $e \in[0, \bar{e}], k<b$ the agent learns the payoff of all projects with probability $e$ and remains uninformed with probability $1-e$. We assume that the principal is risk neutral and that the agent is infinitely risk averse with respect to income. Therefore, the agent is not responsive to monetary incentives and he agrees to receive a fixed wage $w$ equal to his

\footnotetext{
${ }^{8}$ In the next section $B$ is endogenized by the intensity of competition in product markets.

${ }^{9}$ Alternatively, one can assume that the agent receives a benefit of $\beta b$ when the principal's preferred project is implemented with $(0 \leq \beta \leq 1)$. Here, to simplify exposition we simply set $\beta=0$.
} 
opportunity cost. His incentives to gather information on projects will be directly related to the private non pecuniary benefit $b$ he gets from his "best" project.

Firms can choose between three types of organizations, a P-organization in which the CEO/owner has formal power, an A-organization in which the CEO delegates formal power to the agent, and an O-organization in which the principal has formal power and in which the agent exerts minimum effort. The O-organization can be thought of as a single managed firm (run by the principal) without an internal hierarchy. The agent is employed but is not doing anything useful, since the agent's effort is assumed to be not contractible.

We first compute the Nash equilibria in information collection and the resulting payoffs under the $\mathrm{P}$-organization and under the A-organization, respectively. Then we examine which of these organizations yield higher utility to the principal and is preferred by her. We postpone the analysis of the O-organization to the next section.

\section{P-Organization}

Consider first the P-organization. Under the P-organization the principal has formal power in the firm. The principal's and the agent's expected payoffs are

$$
\begin{aligned}
& u_{P}=E B+(1-E) e \alpha B-g_{P}(E)-w \\
& u_{A}=(1-E) e b-g_{A}(e)
\end{aligned}
$$

With probability $E$, the principal becomes fully informed about her payoffs and picks her preferred project with monetary payoff $B$, while the agent receives 0 . With probability $1-E$, the principal remains uninformed about payoffs. The agent may then learn with probability $e$ and suggest his best project to the principal (who accepts it). The principal receives a monetary payoff $\alpha B$ while the agent gets his best private benefit $b$. In this case the informed agent has real power in the firm. If none of the two agents find out which is their preferred project, production does not take place (the other $m-2$ projects yield large negative payoffs). If both agents engage in information collection, the decision rights reside in the principal (who has formal power).

The first order conditions of the two parties with respect to efforts $E$ and 
$e$ are

$$
\begin{array}{rlr}
\text { Principal }: & B(1-e \alpha)=g E \\
\text { Agent }: & e=\bar{e} \text { if } k \leq b(1-E) \\
& =0 \text { if } k>b(1-E)
\end{array}
$$

The conditions highlight the trade-off between the principal's control and the agent's initiative. The principal supervises more the higher her stake in the project (the larger $B$ ), the larger the conflict of interest between the principal and the agent (the lower $\alpha$ ) and the lower the agent's effort $e$. The agent, in turn, has more initiative the higher her stake (the larger $b$ ) and the lower the principal's interference (the lower $E$ ). Thus, control comes with the cost of loosing the agent's initiative.

The Nash equilibrium level of efforts under the P-organization are ${ }^{10}$

$$
\begin{aligned}
e_{P}^{*}=\bar{e}, \text { and } E_{P}^{*}=\frac{B(1-\bar{e} \alpha)}{g} & \text { when } B \leq \widetilde{B}_{P}(\alpha) \\
e_{P}^{*}=0, \text { and } E_{P}^{*}=\frac{B}{g} & \text { when } B>\widetilde{B}_{P}(\alpha)
\end{aligned}
$$

with

$$
\widetilde{B}_{P}(\alpha)=\frac{g(1-k / b)}{1-\bar{e} \alpha}
$$

$\widetilde{B}_{P}(\alpha)$ is the threshold level of profits at which the agent's initiative is killed under the P-organization. For $B$ 's above the level $\widetilde{B}_{P}(\alpha)$, the principal exerts the effort $E_{P}^{*}$ and kills the initiative of the agent.

\section{A-Organization}

Consider now the A-organization. In this organization the principal delegates formal power to the agent. The two parties' expected payoffs are then

$$
\begin{aligned}
& v_{P}=e \alpha B+(1-e) E B-g_{P}(E)-w \\
& v_{A}=e b-g_{A}(e)
\end{aligned}
$$

\footnotetext{
${ }^{10}$ There are three possible Nash equilibria in effort levels. We select the equilibrium with the highest agent's effort which is also the one preferred by the principal. For a discussion of the three Nash equilibria see Aghion and Tirole 1997.
} 
Now the agent chooses his preferred project when informed. Under this organization the principal is prevented from overruling the agent's decision when both have acquired information. When the principal is informed and the agent is uninformed, the principal suggests her best project, which is then implemented by the agent. In this case the principal has real power in the firm. With $b>k$, the Nash equilibrium effort levels under the A-organization $\operatorname{are}^{11}$

$$
e_{A}^{*}=\bar{e} \text { and } E_{A}^{*}=\frac{B(1-\bar{e})}{g}
$$

The advantage of delegating formal power to the agent is that the agent has more initiative to become informed. In our specification, the agent will always provide maximum effort under the A-organization while his initiative will be killed under the $\mathrm{P}$-organization for profits of the principal large enough. ${ }^{12}$

\section{The Choice of Firm Organization}

We turn now to determine the optimal firm organization. We now ask how the parties' informational efforts respond to exogenous changes in the payoff $B$ under the $\mathrm{P}$-organization and under the A-organization, respectively. ${ }^{13} \mathrm{We}$ solve for the subgame perfect equilibrium in effort levels $E^{*}, e^{*}$ under each mode of organization when profits gradually increase.

Two cases can be distinguished.

Case 1: $B \leq \widetilde{B}_{P}(\alpha)$

At this profit level both firm organizations keep the agent's initiative alive. The utility levels of the principal under the two forms of organization

${ }^{11}$ When $\beta>0$, we can show that there exists a threshold $\widetilde{B}_{A}$ given by

$$
\widetilde{B}_{A}=\frac{g(1-k / b)}{\beta(1-\bar{e})}
$$

such that the agent's initiative is killed under the A-organization when $B>\widetilde{B}_{A}$. Intuitively, above the threshold level $\widetilde{B}_{A}$ the principal's stakes are so high that she acquires information $E_{A}^{*}$ leading to a high probability of intervention which, in equilibrium, leads to minimum agent's effort $e_{A}^{*}=0$.

${ }^{12}$ The O-organization is a $\mathrm{P}$-organization with minimum effort by the agent. We postpone the analysis of the O-organization to the next section.

\footnotetext{
${ }^{13}$ We endogenize $B$ by product market competition in the next section.
} 
are simply

$$
u_{P}^{*}=g \frac{\left(E_{P}^{*}\right)^{2}}{2}+e_{P}^{*} \alpha B-w \quad \text { and } \quad v_{P}^{*}=g \frac{\left(E_{A}^{*}\right)^{2}}{2}+e_{A}^{*} \alpha B-w
$$

Given that $e_{P}^{*}=e_{A}^{*}=\bar{e}$, and that $E_{P}^{*}>E_{A}^{*}$ in this regime, it follows that $u_{P}^{*}>v_{P}^{*}$. Thus, the $\mathrm{P}$-organization yields higher utility to the principal.

Case 2: $\widetilde{B}_{P}(\alpha)<B$

At this profit level, the P-organization kills the agent's effort $e_{P}^{*}=0$, while he exerts maximal effort $e_{A}^{*}=\bar{e}$ under the A-organization. The principal's expected utilities under the two organizations, respectively are given by

$$
u_{P}^{*}=\frac{B^{2}}{2 g}-w \text { and } v_{P}^{*}=\frac{(1-\bar{e})^{2} B^{2}}{2 g}+\bar{e} \alpha B-w
$$

$u_{P}^{*}>v_{P}^{*}$ and thus the principal prefers the $\mathrm{P}$-firm over the A-firm when

$$
B>\bar{B}(\alpha)=\frac{2 g \alpha}{2-\bar{e}}
$$

$\bar{B}(\alpha)$ is the threshold level of profits at which the principal is indifferent between loosing control while keeping the agent's initiative as in the A-organization and keeping control but loosing the agent's initiative as in the O-organization. When $B>\bar{B}(\alpha)$, the principal prefers to exert control and to loose the agent's initiative and she opts for the O-organization.

We summarize the preceding discussion in the following proposition.

Proposition 1 For $\bar{B}(\alpha)<\widetilde{B}_{P}(\alpha)$ the P-organization yields higher utility to the principal than the A-organization for all values of $B$.

For $\widetilde{B}_{P}(\alpha)<\bar{B}(\alpha)$, three organizations may emerge as profits gradually increase.

- For $B \leq \widetilde{B}_{P}(\alpha)$, the principal prefers the P-firm over the A-firm with $e_{P}^{*}=\bar{e}$ and $E_{P}^{*}=\frac{B(1-\alpha \bar{e})}{g}$;

- For $\widetilde{B}_{P}(\alpha)<B<\bar{B}(\alpha)$, the A-firm yields higher utility to the principal than the $P$-firm with $e_{A}^{*}=\bar{e}$ and $E_{A}^{*}=\frac{B(1-\bar{e})}{g}$;

- For $\bar{B}(\alpha) \leq B$, the $O$-firm yields higher utility to the principal than the $A$-firm with $e_{P}^{*}=0$ and $E_{P}^{*}=\frac{B}{g}$. 
Intuitively, the mode of organization matters for incentives inside the firm at intermediate levels of profits only. At low and high profit levels there is no trade-off between control and initiative. At low profit levels, the principal monitors and intervenes little because her stakes are small and she cares little. Therefore, the P-organization gives sufficient initiative to the agent. At high profit levels, the principal's stakes are so large that she intervenes even under the A-organization leading to minimum effort by the agent even when he is given formal power in the firm. Therefore, the principal might as well keep control by choosing the O-organization. At intermediate levels of profits there is a trade-off between control and initiative and the principal delegates formal power to her agent to keep his initiative and the A-organization emerges as the optimal mode of organization.

The firm's optimal choice of organization is illustrated in Figure 2. The $\tilde{B}_{P}(\alpha)$ - curve captures the cost of having control in the firm in terms of the loss of the agent's initiative. The $\bar{B}(\alpha)$ - curve captures the gain of having control in terms of the firm's/principal's profits. From Proposition 1 we know that for profit levels below the $\tilde{B}_{P}(\alpha)$ curve the benefit of control outweights its costs and the firm chooses the P-organization. In fact, at these levels of profits there are no costs of control, since the agent's initiative can be kept alive under the P-organization. For profit levels in between the $\tilde{B}_{P}(\alpha)$ - and the $\bar{B}(\alpha)$ - curve, the cost of control outweights the benefit and the firm goes for the A-organization. For profit levels above the $\bar{B}(\alpha)$ - curve, the benefit of control again outweights its costs and the firm chooses the O-organization.

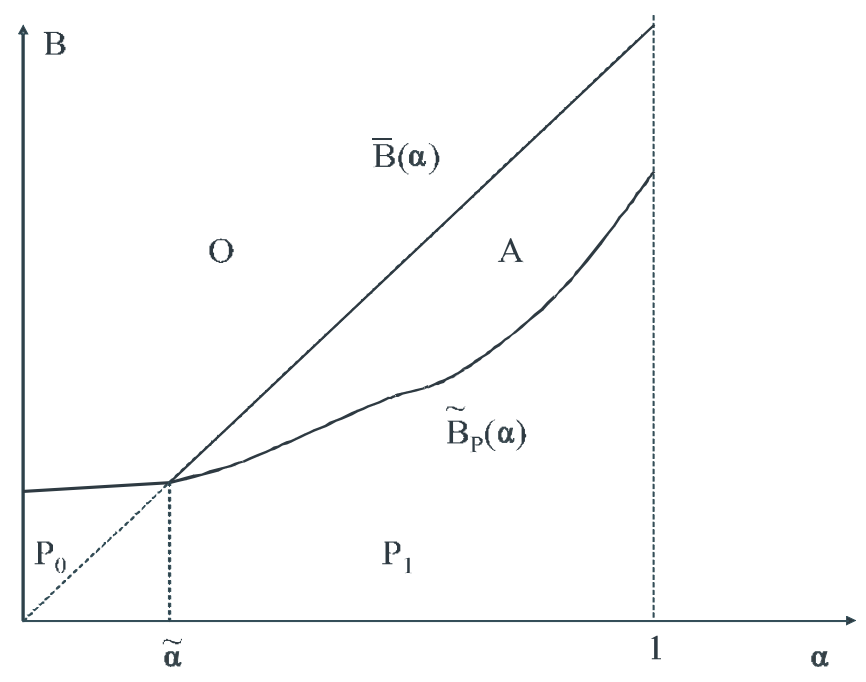

Figure 2: The Optimal Choice of Firm Organization 


\section{Market Competition and Power Struggle}

We incorporate now the choice of firm organization into the production side described in section 2. We endogenize profits $B$ and the power struggle in firms $\alpha$ in this section. Recall the distinction between formal and real power in the firm. Consider two types of firms depending on who has real (as opposed to formal) power in the organization. Firms in which the principals' preferred project is implemented produce the good with production cost $c_{i}=$ $c_{B}$. Call these firms "real P-firms". Similarly firms in which the agent's preferred project is implemented produce the good with production $\operatorname{cost} c_{i}=$ $c_{b}=\varphi c_{B}$ and $\varphi>1$. Call these firms "real A-firms". The idea here is that the agent does not always choose the cost minimizing project but rather one that is best for him and maximizes his perks. Thus, even in a 'formal P-firm' in which the principal keeps formal control, the agent's preferred high cost project may get implemented. This will happen when the principal decides not to get informed and to rubber stamp the agent's suggestion. This is a 'real A-firm' in a formal P-firm equilibrium.

$>$ From (??) we can rewrite the principal's profits when her best project is implemented as

$$
B=\pi\left(c_{B}\right)=\frac{L}{4 \gamma}\left[c_{D}-c_{B}\right]^{2}=\frac{L c_{B}^{2}}{4 \gamma}\left[\widetilde{c}_{D}-1\right]^{2} \quad \text { with } \quad \widetilde{c}_{D}=\frac{c_{D}}{c_{B}}
$$

$\widetilde{c}_{D}$ is the cost gap between firms with zero profits $c_{D}$ and the low cost P-firms $c_{B}$. The smaller this gap the harder it is to earn positive profits in the market. Thus, $\widetilde{c}_{D}$ reflects the thoughness of competition that a firm faces.

The conflict of interest between the principal and her agent $\alpha$ can also be expressed as a function of the cost gap $\widetilde{c}_{D}$

$$
\alpha=\frac{\pi\left(c_{b}\right)}{\pi\left(c_{B}\right)}=\left[\frac{\widetilde{c}_{D}-\varphi}{\widetilde{c}_{D}-1}\right]^{2}
$$

The power struggle in firms becomes more intense ( $\alpha$ becomes smaller) with a decline in relative profits between an A-firm $\pi\left(c_{b}\right)$ in which the agent runs the firm and a P-firm $\pi\left(c_{B}\right)$ in which the principal has power in the firm. Relative profits between these two types of firms decline with tougher competition (with smaller $\widetilde{c}_{D}$ ), because high-cost A-firms' revenues go down by more than revenues of low-cost P-firms. A-firms try to fight the loss in revenues by lowering mark-ups by more than $\mathrm{P}$-firms. With more intense 
competition, it matters more who runs the firm and delegation of power to the agent becomes more costly to firms.

To see this we express prices, output, mark-ups, and revenues of P-firms and A-firms, respectively as a function of $\widetilde{c}_{D}$.

$$
\begin{gathered}
q_{B}=q\left(c_{B}\right)=L c_{B} \frac{\widetilde{c}_{D}-1}{2 \gamma} \quad \text { while } q_{b}=q\left(c_{b}\right)=L c_{B} \frac{\widetilde{c}_{D}-\varphi}{2 \gamma} \\
p_{B}=p\left(c_{B}\right)=c_{B} \frac{\widetilde{c}_{D}+1}{2} \quad \text { while } p_{b}=p\left(c_{b}\right)=c_{B} \frac{\widetilde{c}_{D}+\varphi}{2} \\
r_{B}=r\left(c_{B}\right)=\frac{L c_{B}^{2}}{4 \gamma}\left(\widetilde{c}_{D}^{2}-1\right) \quad \text { while } \quad r_{b}=r\left(c_{b}\right)=\frac{L c_{B}^{2}}{4 \gamma}\left(\widetilde{c}_{D}^{2}-\varphi^{2}\right) \\
\pi_{B}=\pi\left(c_{B}\right)=\frac{L c_{B}^{2}}{4 \gamma}\left[\widetilde{c}_{D}-1\right]^{2} \quad \text { while } \quad \pi_{b}=\pi\left(c_{b}\right)=\frac{L c_{B}^{2}}{4 \gamma}\left[\widetilde{c}_{D}-\varphi\right]^{2} \\
m_{B}=m\left(c_{B}\right)=c_{B} \frac{\widetilde{c}_{D}-1}{2}, \\
m_{b}=m\left(c_{b}\right)=c_{B} \frac{\widetilde{c}_{D}-\varphi}{2} .
\end{gathered}
$$

Low cost P-firms set lower prices $p_{B}$, produce larger outputs $q_{B}$, and earn larger revenues $r_{B}$, and profits $\pi_{B}$ than high-cost A-firms $\left(p_{b}, q_{b}, r_{b}, \pi_{b}\right)$. They also set larger mark-ups over price $m_{B}$ compared to A-firms $m_{b}$.

The two relationships (11) and (12) describe how $\widetilde{c}_{D}$, jointly affects profits and the power struggle in firms. Eliminating $\widetilde{c}_{D}$, they define a relationship between $B$ and $\alpha$ that has to be satisfied by any firm. From (11) we get

$$
\widetilde{c}_{D}=1+\frac{2}{c_{B}} \sqrt{\frac{\gamma}{L}} \sqrt{B}
$$

and from (12) we have

$$
\widetilde{c}_{D}=\frac{\varphi-\sqrt{\alpha}}{1-\sqrt{\alpha}}
$$

Therefore, the relationship between $B$ and $\alpha$ is given by

$$
B=\widehat{B}(\alpha)=\left[\frac{\varphi-1}{1-\sqrt{\alpha}}\right]^{2} \frac{L}{\gamma} \frac{c_{B}^{2}}{4}
$$


The construction of the $\widehat{B}($.$) curve is described in Figure 3$. The curve $(P P)$ in quadrant I plots equation (11) and shows how the firm's profits $B$ vary with $\widetilde{c}_{D}$ (relationship 11)). The curve is positively sloped, because when $\widetilde{c}_{D}$ declines and competition becomes tougher, profits decline as revenues and markups become smaller. The curve $(\alpha \alpha)$ in quadrant II plots equation (12) and shows how $\widetilde{c}_{D}$ affects the conflict of interest inside firms $\alpha$ (relationship (12)). The curve is positively sloped, because when $\widetilde{c}_{D}$ declines and competition becomes tougher delegating power to the agent becomes more costly to firms and hence the conflict of interest in firms rises ( $\alpha$ becomes smaller). Quadrant III plots the $45^{0}$-line making sure that the two curves $(\alpha \alpha)$ and $(P P)$ are drawn for the same value of $\widetilde{c}_{D}$. Then the $\widehat{B}($.$) curve is obtained$ in quadrant IV which shows how $\alpha$ affects profits $B$. The curve is positively sloped, because with an increase in $\widetilde{c}_{D}$ and $\alpha$ competition and the power struggle in firms decline and firms earn higher profits. A given value of $\alpha$ in quadrant IV is associated with a value of $\widetilde{c}_{D}$ in quadrant II which results in a level of profits $B$ in quadrant I, generating a point $M$ on curve $\widehat{B}($.$) in$ quadrant IV.

The appendix shows that $\widehat{B}($.$) satisfies \widehat{B}(0)>0$ and $\widehat{B}(1)=+\infty$ and is positively sloped in the space $(B, \alpha)$. A downward move along $\widehat{B}($.$) is$ associated with an increase in market competition (a decrease in $\widetilde{c}_{D}$ ).

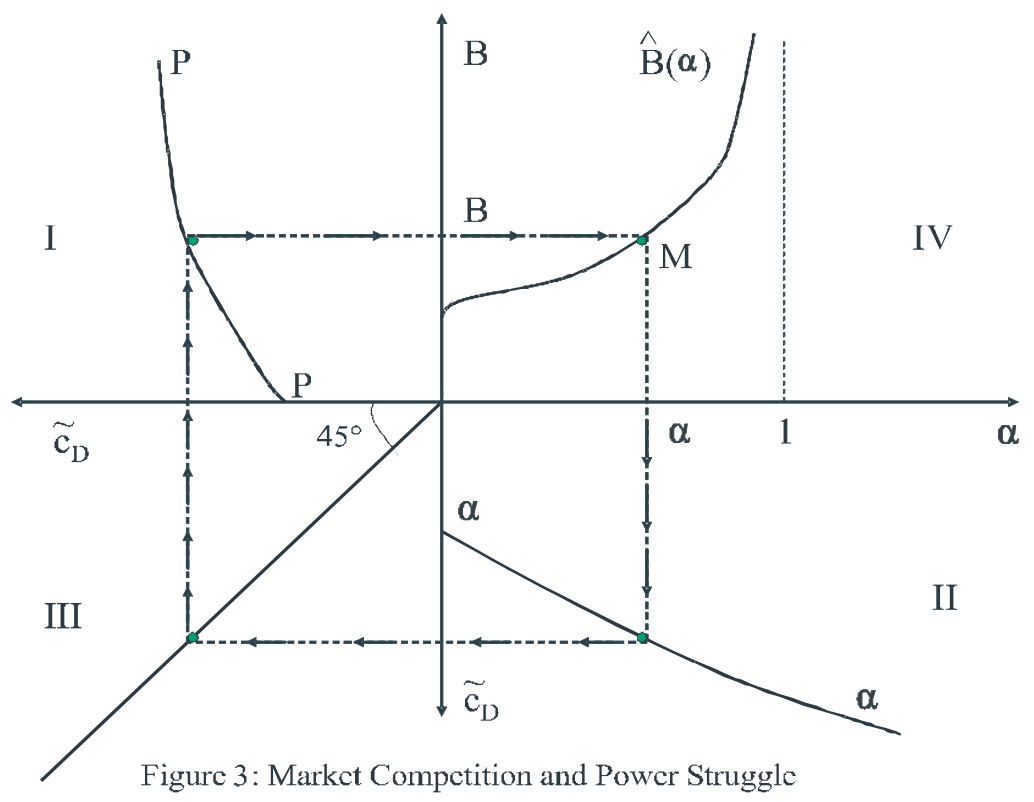




\subsection{Industry Equilibrium with Free Entry}

We derive now the industry equilibrium in which the free entry conditions have to be fulfilled for a given choice of firm organization. The timing of events is as follows. In a first stage, firms decide whether or not to enter the market and to hire an agent to monitor projects. At this stage, there is free entry. In a second stage, firms decide who has formal power in the organization by choosing between the formal P-firm and the formal A-firm. In a third stage, information collection efforts are realized by the two parties and a project is selected. This, in turn, determines who has real power in the organization. Finally there is production, consumption and factor market clearing.

The free entry conditions for a given choice of firm organization can be written as $\operatorname{Max}\left\{U_{P}(B), U_{A}(B), U_{0}(B)\right\}=w=1$ where $U_{P}(B), U_{A}(B)$, and $U_{0}(B)$ are the profit levels of the firm gross of the wage of the agent under each organization $P, A$ or $O{ }^{14}$ The "Max" argument in the free entry conditions reflects the fact that each firm decides about its optimal type after market entry. Three types of free entry equilibria are possible:

i) Equilibrium with P-organization and $e_{P}^{*}=\bar{e}$

The free entry condition in such a regime is

$$
U_{P}(B)=g \frac{\left(E_{P}^{*}\right)^{2}}{2}+\bar{e} \alpha B=1
$$

This gives a unique positive solution $B_{P}=B_{P}^{*}(\alpha)$ which is the free entry profit level that firms require to enter the market with a formal Porganization. Obviously, an equilibrium in this regime exists if and only if $B_{P}^{*}(\alpha) \leq \widetilde{B}_{P}(\alpha)$

ii) Equilibrium with A-organization and $e_{A}^{*}=\bar{e}$.

The free entry condition in such a regime is

$$
U_{A}(B)=g \frac{\left(E_{A}^{*}\right)^{2}}{2}+\bar{e} \alpha B=1
$$

\footnotetext{
${ }^{14}$ With the previous notation these profit levels are

$U_{P}(B)=u_{P}+w=g \frac{\left(E_{P}^{*}\right)^{2}}{2}+e_{P}^{*} \alpha B=\frac{B^{2}(1-\alpha \bar{e})^{2}}{2 g}+\bar{e} \alpha B$

$U_{A}(B)=u_{A}+w=g \frac{\left(E_{A}^{*}\right)^{2}}{2}+e_{A}^{*} \alpha B=\frac{B^{2}(1-\bar{e})^{2}}{2 g}+\bar{e} \alpha B$

$U_{0}(B)=u_{0}+w=g \frac{\left(E_{0}^{*}\right)^{2}}{2}=\frac{B^{2}}{2 g}$
} 
The free entry condition gives a unique positive solution $B_{A}=B_{A}^{*}(\alpha)$. An equilibrium in this regime exists if and only if $\widetilde{B}_{P}(\alpha) \leq B_{A}^{*}(\alpha)<\bar{B}(\alpha)$.

iii) Equilibrium with O-organization and $e_{P}^{*}=0$

Finally the free entry condition in this regime is

$$
U_{0}(B)=g \frac{\left(E_{0}^{*}\right)^{2}}{2}=1
$$

which gives the solution $B_{P}=\sqrt{2 g}$. Such an equilibrium exists when $\sqrt{2 g}>\bar{B}(\alpha)$.

The labor market is automatically cleared by the output adjustment on the numeraire good 0 which pins down the wage rate to 1 .

\subsubsection{Free Entry and Power Struggle}

Next, we analyze how firms' incentives to enter the market are affected by the anticipated power struggle in firms. In terms of the model, we look at how the equilibrium conditions for free entry for P-firms, A-firms, and $\mathrm{O}$ firms, respectively are affected by changes in $\alpha$. We do this with the help of Figure 4 . Recall that the curves $B_{P}^{*}(\alpha)$ and $B_{A}^{*}(\alpha)$ are the free entry profit levels that a firm requires to enter the market as a P-firm and as an Afirm, respectively. Both curves slope down with $\alpha$, since both firms revenues increase with $\alpha$ and thus firms require a lower profit to enter the market. The $B_{A}^{*}(\alpha)$ curve lies above the $B_{P}^{*}(\alpha)$ curve, since for any given $\alpha$, firms with an A-organization anticipate that their profits will be reduced when the agent has power in the firm. Hence, A-firms require a larger profit to enter the market. When preferences between principals and agents are perfectly congruent (when $\alpha=1$ ), there is no conflict of interest and the organization of the firm stops to matter for market entry. Both types of firms will choose the same cost minimizing project (at $\alpha=1$ the two curves collapse to the same required profit value $\left.B_{A}^{*}(\alpha)=B_{P}^{*}(\alpha)\right)$. 


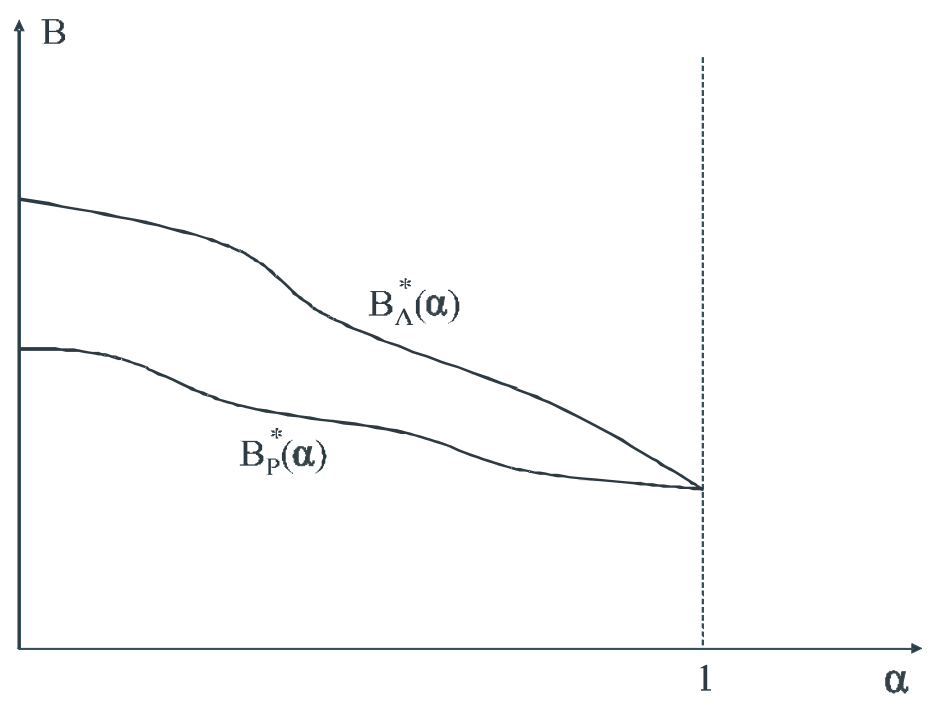

Figure 4: Equilibrium Entry

\subsection{Equilibrium Organization with Free Entry}

Consider now the structure of organizational equilibria with free entry which are determined in Figure 5. The figure combines the profit maximizing choice of organization of Figure 2 and the free entry conditions of Figure 4 to analyze the equilibrium mode of organization under free entry. The two curves $\tilde{B}_{P}(\alpha)$ and $\bar{B}(\alpha)$ from Figure 2 determining the optimal firm organization are plotted as well as the two curves $B_{P}^{*}(\alpha)$ and $B_{A}^{*}(\alpha)$ from Figure 4 describing the free entry profit levels for P-firms with agent's effort (i.e. $e=\bar{e}$ ) and for A-firms. In addition, the horizontal line $B_{0}^{*}=\sqrt{2 g}$ is giving the free entry profit level for O-firms.

The bold line in Figure 5 describes the nature of the free entry corporate equilibria as a function of the power struggle in firms $\alpha$. Several points are worth noticing. First, at $\alpha=1$, the mode of organization stops to matter. At this value of $\alpha$, preferences of principals and managers are perfectly congruent and there is no conflict in the firm. Second, with a decrease in $\alpha$, the equilibrium firm organization moves from the central $\mathrm{P}$-organization with power at the top of the organization to the decentral A-organization with power delegated to the manager and finally to the single managed O-organization. Typically, with an increase in $\alpha$, the stakes rise and firms require a larger level of profit $B^{*}$ to enter the market under both organizations. As the conflict of interest in firms rise, principals start to monitor. Initially, for large values of $\alpha$ in the range of $\left[\alpha_{P}, 1\right]$, the firms' free entry stakes $B^{*}$ are no too 
high. Therefore, firms' monitoring does not kill the initiative of agents even under the P-organization. Hence, firms choose the latter. However, when $\alpha$ goes down and the power struggle in firms increases, the required stakes to enter the market are high enough to kill the initiative of agents under the $\mathrm{P}$-organization but not under the A-organization. There is a trade-off between control and initiative. The A-organization emerges as a corporate equilibrium for values of $\alpha$ in $\left[\bar{\alpha}, \alpha_{A}\right]$ ). Finally, as $\alpha$ decreases further (i.e for values of $\alpha$ smaller than $\bar{\alpha}$ ), the required profit level for market entry increases further until the stakes for firms become so high that firms favor control and loose the initiative of managers and the O-firm emerges as the equilibrium organization.

Statement 1: When the power struggle in firms increases, the corporate equilibrium organization moves from the central P-organization to the decentral A-organization to the single managed O-organization.

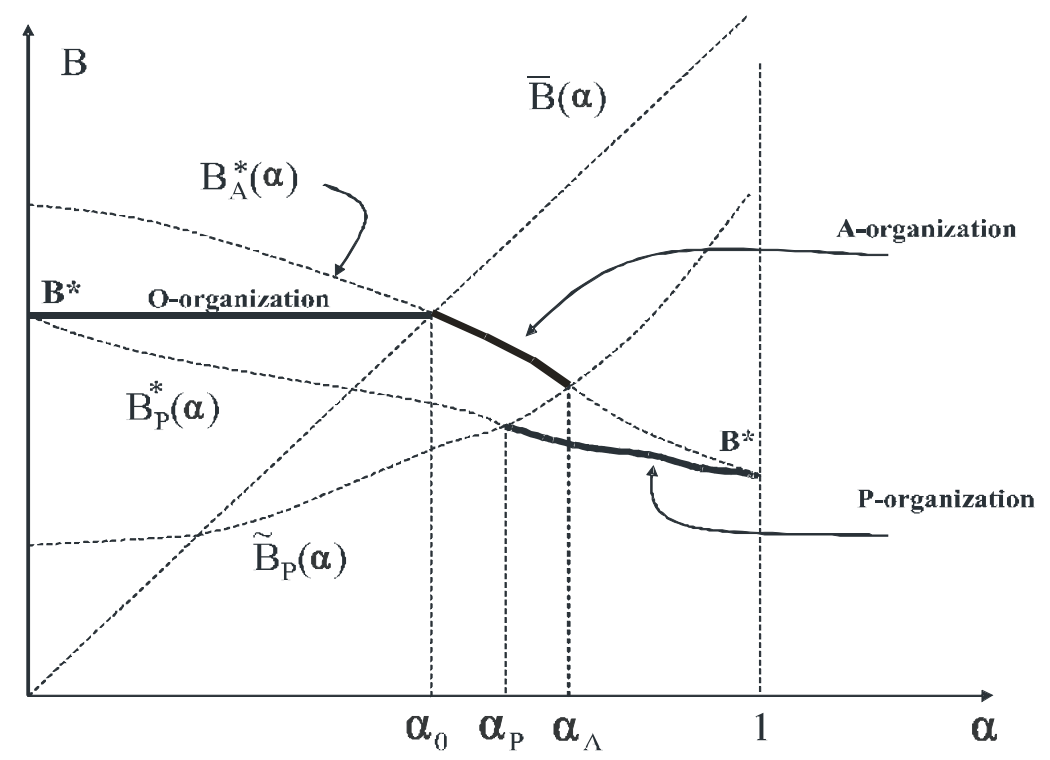

Figure 5: Free Entry Equilibrium Organization

\subsection{Corporate Equilibrium and Competition}

We are finally ready to describe the corporate equilibrium organization. This is done in Figure 6 which explores how the free entry organizational equilibria we have just derived in the previous section interact with the thoughness of competition and the power struggle in firms. The $B^{*} B^{*}$ curve (derived 
in Figure 5) determines free entry profits and the profit maximizing choice of firm organization. The $B=\widehat{B}(\alpha)$ curve (derived in Figure 4) determines profits, the thoughness of competition in the market as well as the power struggle in firms. An equilibrium $E=\left(B^{e}, \alpha^{e}\right)$ is defined by an intersection point of the two curves. Since $B^{*} B^{*}$ is downward sloping in $\alpha$ and $\widehat{B}(\alpha)$ is increasing in $\alpha$, we show in the appendix that such an organizational equilibrium $\left(B^{e}, \alpha^{e}\right)$ always exists. The model is then solved recursively. Once the equilibrium values of $B^{e}$ and $\alpha^{e}$ and an equilibrium organizational regime $i \in\{P, A, O\}$ are obtained, one can derive the corresponding threshold cost $\widetilde{c}_{D}^{i}$ in quadrant II of Figure 6. Similarly, the equilibrium level of monitoring by firms $E_{i}$ is obtained, from which we then compute the equilibrium average costs $\bar{c}^{i}$, the equilibrium number of effective firms $N_{i}$, the number of entering firms $M_{i}=N_{i} /\left(E_{i}+\left(1-E_{i}\right) e\right)$ and output, revenues and mark-up levels of low costs P-firms and high costs A-firms. Finally, the labor market equilibrium gives the output level of the numeraire good 0 .

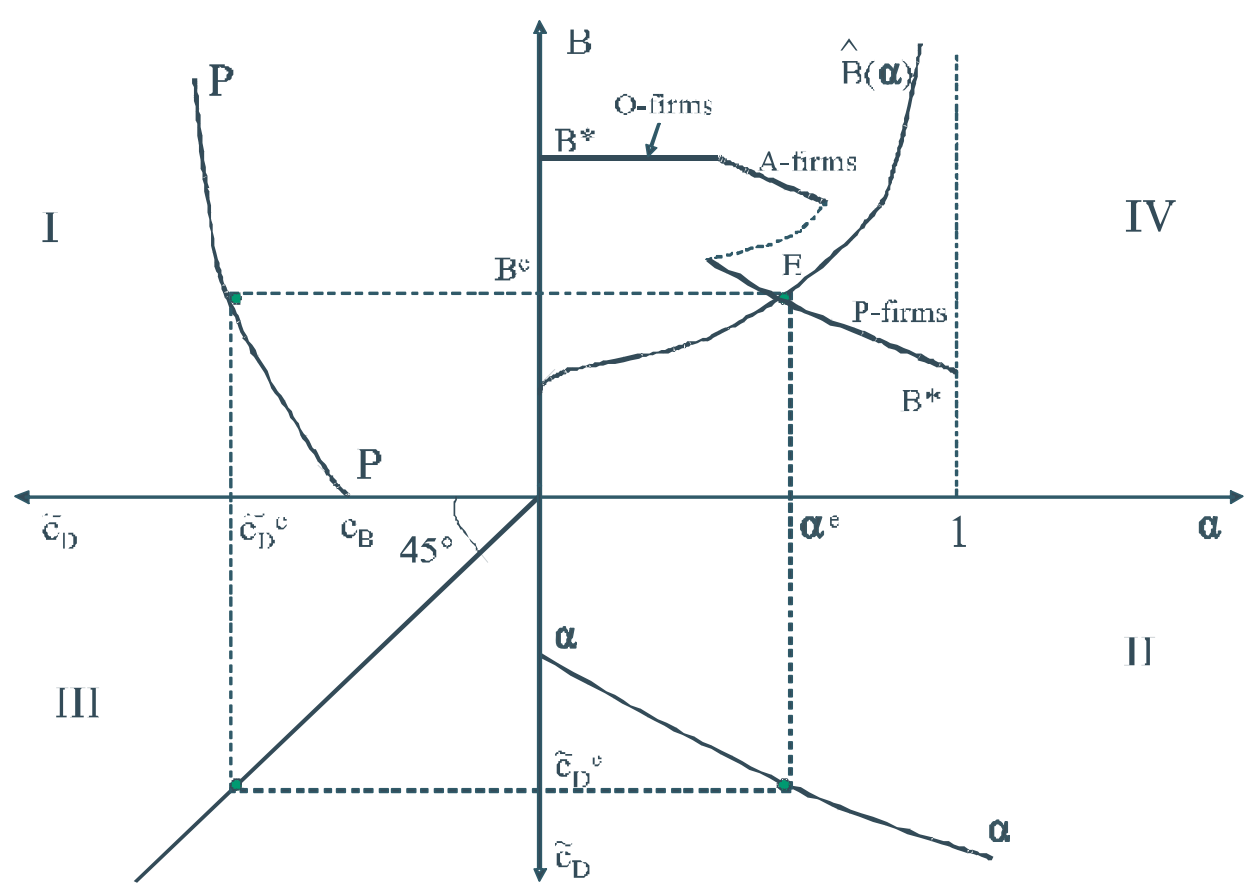

Figure 6: Corporate Equilibrium and Competition 


\section{Market Size and Corporate Equilibrium}

Consider now the comparative statics associated with a change in market size $L$. A change in market size affects profits and the toughness of competition between firms. This, in turn, affects the power struggle in firms and the optimal firm organization.

The effect of a change in market size $L$ is illustrated in Figure 7. We know from (11) that a larger market increases firms' profits as output per firm and revenues increase. This is reflected by an upward shift of the (PP) curve in quadrant $I$ of Figure 7 . At the same time a change in $L$ does not affect the conflict curve $(\alpha \alpha)$ in quadrant II. Given that profits of high costs and low costs firms are both directly proportional to market size, a change in $L$ has no direct effect on the conflict of interest $\alpha$, everything else being equal. Thus, an increase in $L$ shifts up the curve $\widehat{B}(\alpha)$ in quadrant IV of Figure 7 . Note also that the free entry curve $B^{*} B^{*}$ is not affected by a change in $L$

As a consequence, market size affects the equilibrium organization of firms. An increase in $L$ makes the equilibrium point $E$ (intersection of $\widehat{B}(\alpha)$ and $B^{*} B^{*}$ ) move along $B^{*} B^{*}$ upward from a P-equilibrium with power at the top of the organization to an A-equilibrium with power delegated to the divisional level, to finally a single managed O-equilibrium regime without internal hierarchies. Note also that with an increase in market size, $\alpha$ is moving leftward along the $B^{*} B^{*}$ curve. Hence, the conflict of interest in the firm increases with an increase in $L$. Finally, in quadrant II of Figure 7 , an increase in $L$ is increasing the toughness of competition in the market (decreases $\widetilde{c}_{D}$ ) 


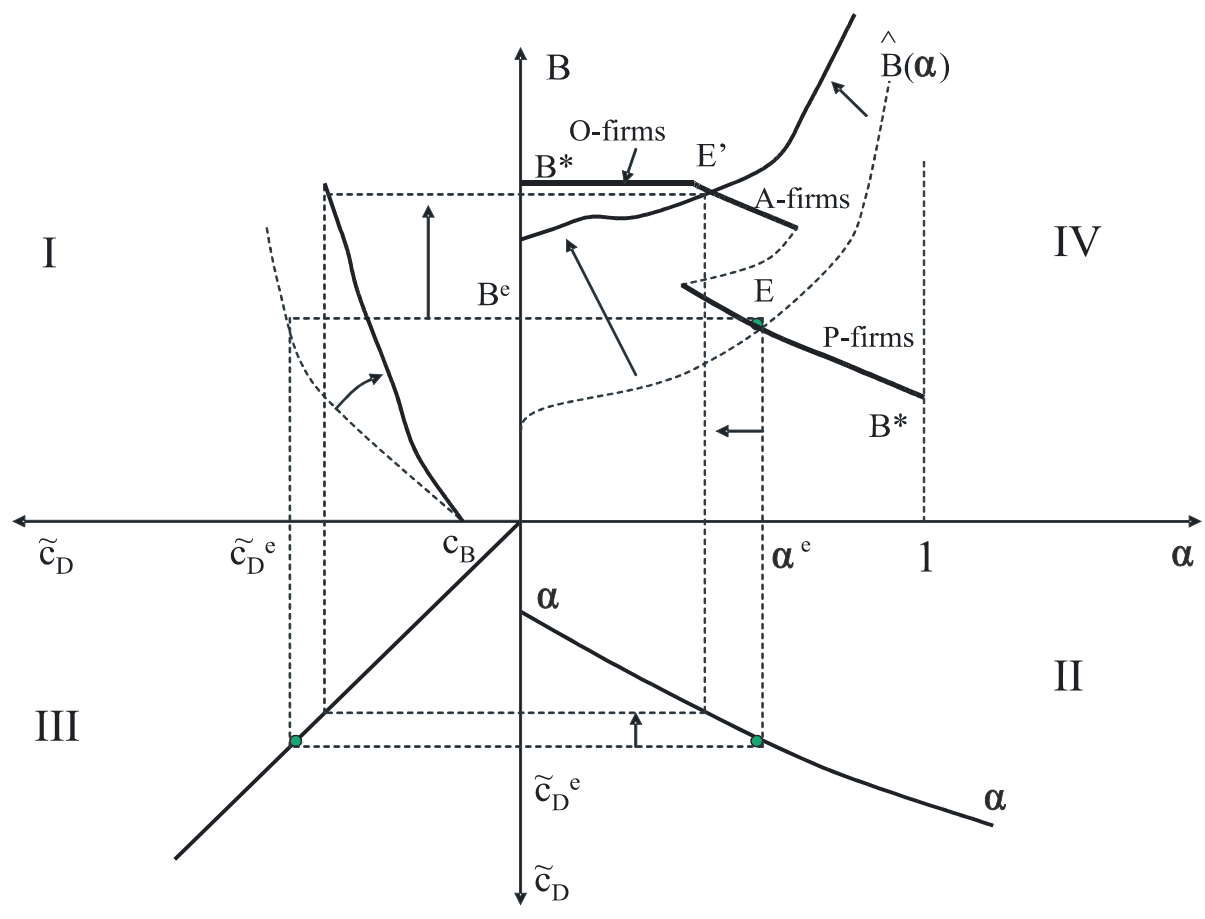

Figure 7: A Change in Market Size

Intuitively, an increase in market size increases firms' outputs and profits, inducing firm entry, tougher competition and smaller markups. With increased competition delegation of power becomes more costly and tends to increase the power struggle between principals and managers (lower $\alpha$ ). A larger conflict of interest in firms and bigger profits, in turn stimulate monitoring by principals (increased effort $E$ ), making it more likely that the initiative of agents is crowded out under a central P-organization. Initially, when the market is small, profits and the conflict of interest in firms is small. Therefore, principals in firms monitor only little and do not kill the initiative of agents under the $\mathrm{P}$-organization. There is no trade-off between control and initiative. Hence, firms choose the latter. However, when market size keeps increasing and takes intermediate levels, profits, competition and the conflict in firms become sufficiently large to kill the initiative of agents under the Porganization. There is a trade-off between control and initiative. Principals delegate power to agents to keep the initiative alive and the A-organization emerges as a free entry corporate equilibrium. When market size keeps increasing further profits, competition, and the power struggle in firms become so large that principals in firms prefer control no matter what. There is again no trade-off between control and initiative and the single managed O-firm without agents' effort emerges as the equilibrium organization. 
Note that when the market is neither too small nor too large there are more than one equilibrium mode of organization. One equilibrium is the P-organization with high agents' effort and another is the A-organization. These multiple equilibria arise due to a "strategic complementarity " among firms at the decision stage of optimal firm organization. At an intermediate level of market size the attractiveness between the two modes of organization depends on the organizational decisions taken by other firms in the market. Each firm individually would choose the A-organization at this size of the market, since in between the curves $\tilde{B}_{P}(\alpha)$ and $\bar{B}(\alpha)$ the A-organization is optimal. However, when the firm anticipates at this stage that all the other firms will choose the P-organization, then, she also anticipates that competition will be tough in the market. In a $\mathrm{P}$-organizational equilibrium average costs in the industry will be low as the share of low cost firms will be larger than in an A-equilibrium. Hence, firms anticipate that it will be hard to survive competition with a formal A-organization. Therefore, market entry as an A-firm is not profitable and firms' best choice after entry will be to choose a P-organization as well. Similarly, when firms anticipate that all the other firms will choose the A-organization, then they expects to be viable competitors in the market with an A-organization. The multiplicity of organizational equilibria arises due to a coordination problem among firms which comes from the fact that firms' choice of organization affects the toughness of competition in the market. ${ }^{15}$

Moreover, when the organizational equilibrium shifts from $\mathrm{P}$ to A with an increase in market size, the power struggle between principals and managers may decline rather than increase. In fact, in an A-organizational equilibrium, firms have on average higher costs of production than in a P-equilibrium. Agents are more likely to have real power in firms in an A-equilibrium and to implement their best "high cost" project. This in turn reduces the toughness of competition in the economy and hence reduces the conflict of interest in firms. This is illustrated in Figure 8 which shows how $\alpha$ is affected by a change in $L$. For low values of $L$, a P-organizational equilibrium prevails and an increase in market size tends to reduce the value of $\alpha$ within that regime. When $L$ becomes big enough, an A-equilibrium becomes feasible and the

\footnotetext{
${ }^{15}$ Note that the coordination problem among firms disappears in small and large markets. When the market is small firm's organizational choice has a minor effect on the toughness of competition in the market, because there are only a small number of competitors. When the market is larger competition becomes more intensive and the option to choose the P-organization disappears. All firms in the market will choose the A-organization. Thus, in either case, in small and large markets, there is no need to coordinate actions among firms. For the effect of firms' choice of organization on the nature of competition see Marin and Verdier (2006).
} 
conflict in firms declines as $\alpha$ jumps upwards to a higher value. A further increase in $L$ in the A-regime again toughens competition and increases the conflict in firms ( $\alpha$ continues to decline). Finally, when $L$ is increasing even further, the O-firm emerges as the new equilibrium and $\alpha$ keeps declining ${ }^{16}$. This discussion can be summarized in the following statement:

Statement 2: When the size of the market increases, the corporate equilibrium moves from the central P-organization to the decentral A-organization and finally to the single managed $O$-firm. Within each organizational regime $(P, A$ or $O)$, the conflict of interest between principals and managers increases with market size. A shift in the organizational regime from $P$ to $A$ at first reduces the power struggle in firms.

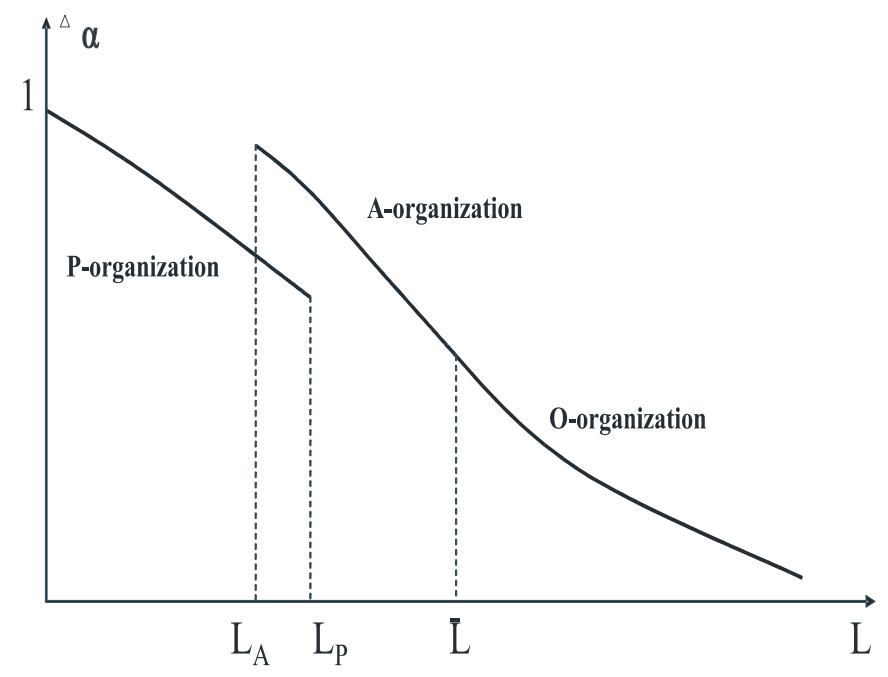

Figure 8: Market Size and Conflict in the Firm

\section{Econometric Evidence}

In this section we use unique survey data of 660 global corporations in Austria (200) and Germany (460) to test the predictions of our theory. We first derive the predictions from the theory. We then examine the relationship between the allocation of power in firms and international trade. Finally, we study the

\footnotetext{
${ }^{16}$ Though it is effectively irrelevant, as in that regime, the agent never has "real power" (his initiative is killed).
} 
relationship between the power struggle in firms and the trade environment. As predicted by the theory, we show that the allocation of power in Austrian and German corporations and their difference described by the facts in Tables 1 to 3 of the introduction can be explained by market size and competition.

\subsection{Predictions}

We start by examining the relationship between international trade and firms' mode of organization. An increase in trade is captured in our model by an increase in market size $L$. From Figure 7 we can derive this relationship. Recall that an increase in market size $L$ shifts up the $\widehat{B}(\alpha)$ curve along the $B^{*} B^{*}$ curve in quadrant IV. Hence, with an increase in $L$ competition becomes more intense $\left(\widetilde{c}_{D}\right.$ declines) and the economy moves from a P-equilibrium with power at the CEO level to an A-equilibrium with power delegated to the division manager, to finally a single managed O-firm. Thus, we have

Prediction 1: In a cross section of countries and firms, firms will have more decentral corporate hierarchies and face tougher competition in larger countries.

Next, we study the relationship between trade shares and firms' mode of organization. Smaller economies will import more varieties from the foreign larger economy as home consumers want to consum all varieties produced in the world economy. Hence, smaller countries will have larger trade shares than larger economies. ${ }^{17}$ As the number of varieties supplied by foreign firms increases in response to trade liberalizations smaller countries will experience a larger movement down along the $\widehat{B}(\alpha)$ - curve in Figure 7 compared to larger countries. This corresponds to an increase in the toughness of competition (along $\widehat{B}(\alpha) \quad \widetilde{c}_{D}$ declines). Hence, in smaller economies it becomes more likely that the corporate equilibrium shifts from a central O-organization to a decentral A-organization in response to trade liberalizations. Thus, we have

Prediction 2: In a cross section of countries and firms, organizational change towards less hierarchical organizations is more likely to happen in smaller countries.

\footnotetext{
${ }^{17}$ For the relationship between trade shares and country size, see Helpman and Krugman (1985).
} 
Finally, we examine the relationship between trade and the power struggle in firms. We can derive this relationship from Figure 7 and Figure 8. In Figure 7 an increase in $L$ shifts up the $\widehat{B}(\alpha)$ curve moving $\alpha$ leftward along the $B^{*} B^{*}$ curve in quadrant IV. As a result, the power struggle in firms increases with an increase in $L$. Hence, we have

Prediction 3: In a cross section of countries and firms, the power struggle between CEOs/owners and managers in firms will be more intense in larger more competitive countries.

Lastly, we study the relationship between corporate organization and the power struggle in firms. We can derive this relationship from Figure 8. A shift in the organizational equilibrium from $\mathrm{P}$ to $\mathrm{A}$ leads to a decline in the power struggle (increase in $\alpha$ ). Thus, we have

Prediction 4: In a cross section of countries and firms, the power struggle between CEOs/owners and managers will be less intense in firms with decentral corporate hierarchies.

\subsection{Specification}

We start by examining the relationship between the power allocation in firms and trade. In order to test Prediction 1 and Prediction 2 we report estimates from regressions of the form

$$
\ln (\text { power })_{i j}=\theta_{1}+\theta_{2} \ln (\text { comp })_{i j}+\theta_{3}\left(\text { nat } * \operatorname{comp}_{i j}\right)+\theta_{4}\left(\text { nat } * \exp _{i j}\right)+\theta_{5}(\# s e g m)_{i j}+\epsilon_{i j}
$$

where (power $)_{i j}$ is the power structure of firm $i$ in country $j$ and it is the mean of several corporate decisions in firm $i$ in country $j$ ranked between 1 (central) and 5 (decentral) depending on whether the CEO/owner or the divisional manager in the firm takes the decision. $(\text { comp })_{i j}$ are dummy variables taking the value 1 and zero otherwise when the firm faces very many competitors and decides not to enter the market (very many), when the firm faces many (many) and few ( $f e w)$ competitors, respectively. In light of Prediction 1 , we test the hypothesis that $\theta_{2}>0$ and that firms decentralize decision power in the corporation in more competitive environments compared to when the firm faces no competitor. In particular, we test the hypothesis that $\theta_{3}>0$ and that country size magnifies the effect of competition on the 
power allocation in firms. ${ }^{18}$ nation is a dummy variable taking the value 1 for the large country Germany and zero for Austria. In light of Prediction 2 , we test the hypothesis that $\theta_{4}<0$ and that the smaller country with the larger trade share is more likely to decentralize power compared to the larger country. We test this hypothesis to account for the stylized fact given in Tables 2 and 3 that firms in the smaller economy Austria have changed their organization faster than firms in Germany. We proxy the trade exposure by (exports $)_{i j}$ which measures exports in percent of sales of firm $i$ in country $j$. Finally, we test for $\theta_{5}>0$ and that an increase in the power struggle in firms (measured by (\#segments) ${ }_{i j}$ ) leads to more delegation in the firm. ${ }^{19}$ $\epsilon_{i j}$ is an error term.

Next, we examine the relationship between the power struggle in firms, competition and market size as stated in Prediction 3 and Prediction 4. We run a regression with the following specification

$\ln (\# \text { segm })_{i j}=\partial_{1}+\partial_{2} \ln (\text { comp })_{i j}+\partial_{3}\left(\right.$ nat $\left.* c o m p_{i j}\right)+\partial_{4} \ln (\text { pow })_{i j}+\partial_{5}(\text { nat } * \text { pow })_{i j}+\epsilon_{i j}$

where $(\# \text { segments })_{i j}$ is a proxy for the power struggle in firms. It measures corporate diversification of firm $i$ in country $j$ and gives the number of business segments in the corporation. We assume that the power struggle in firms increases with the number of business segments in the corporation. The idea here is that the CEO/owner's overload increases with more divisions and with more divisional managers to deal with making it more likely that agents have real power in more diversified firms. ${ }^{20}$ In light of Prediction 3 we test the hypothesis that $\partial_{2}<0$ and that firms reduce the number of business segments with more competition. When the market environment becomes more unfriendly delegation of power becomes more costly and fewer business segments can be sustained in firms. We assume that CEOs/owners take control by reducing the number of business segments and by becoming more specialized. ${ }^{21}$ We also include (nation $*$ competition) to test $\partial_{3}<0$ and that country size makes this effect stronger. To test Prediction 4 we include

\footnotetext{
${ }^{18}$ This follows directly from Figure 7 where larger countries have tougher competition and hence have steeper $\widehat{B}(\alpha)$ - curves than smaller countries.

${ }^{19}$ This follows from Figure 5 and Statement 1.

${ }^{20}$ In the corporate finance literature this is discussed as the 'diversification discount'. For one explanation of the inefficiency of conglomerates, see for example Rajan, Servaes and Zingales (2000).

${ }^{21}$ Conglomerates have been viewed by many as inefficient and many business consultancies argued for a return to 'core competencies'. For a review of this literature see Bolton and Scharfstein (1998).
} 
$\ln ($ power $)$ in the regression. We expect that $\partial_{4}>0$ and that more business segments can be sustained in less hierarchical firms. Finally, we include nation $* \ln ($ power $)$ in the regression to test for the interaction. As $L$ and the corporate equilibrium have opposing effects on the power struggle in firms, we cannot a priori sign the interaction between $\ln$ (power) and (nation) (or alternatively between $\ln ($ power $)$ and (competition)).

\subsection{The Data}

We conducted a survey of 660 global corporations in Austria (200 firms) and in Germany (460 firms) in the period 1997-2001. Due to the length of the questionnaire, we personally visited the firms in Austria and Germany, respectively or conducted the interviews by phone. The data include all publicly traded German DAX firms. The data consist of the organizational part of a full population survey of global corporations in Austria and Germany investing in Eastern Europe. The firms included in the sample are global corporations in the sense that they at least have two subsidiaries outside Austria and Germany, respectively. The organizational data of the sample are unique in several dimensions. They include detailed information on the internal organization of the corporations such as power relations between the CEO and the divisional level, organizational form, incentive system used for its workers, wages and educational qualifications of the firm's workers, detailed data on the financial structure as well as balance sheet information. Table A3 of the data appendix gives summary statistics of all the variables used in this paper. ${ }^{22}$

The left-hand side variable power of equation (17) is obtained from the question 'Who decides over the following issues concerning your corporation, headquarter or the divisional manager, please rank between 1 (central decision taken at the headquarter) and 5 (decentral decision taken at the divisional level)?' The survey then lists 16 (Germany) and 13 (Austria) corporate decisions which are ranked by headquarter of the corporation including the decisions over acquisitions, financial decisions, decisions over new strategy, decisions over transfer pricing, decisions to introduce new product, decisions over R\&D expenditures, decisions over budget, decisions over product price, decisions over wage increase, decision of firing of personnel, and decision of hiring a secretary. ${ }^{23}$ Tables A1 and A2 of the Appendix give a complete

\footnotetext{
${ }^{22}$ For more information on the data see Marin (2006).

${ }^{23}$ In some cases it was ranked by the divisional level, when the firm is a very large conglomerate. In this cases the interview was conducted at the divisional level.
} 
list of the ranking of these decisions in the corporate hierarchy. The variable power is the mean over the 16 (13) corporate decisions ranking for an individual firm ranging between 1 and 5. A firm with a mean of 1 has all 16(13) decisions centrally organized with power at the top of the organization and a firm with a mean of 5 has these decisions decentrally organized with power at the divisional level. As can be seen from Tables A1 and A2 the corporate decisions exhibit a robust ranking in the two countries. The decisions over acquisitions and the financial decisions tend to be taken at the top of the corporation in firms in both countries, while the decisions over R\&D expenditures and the decisions to introduce a new product tend to be shared between the headquarter and the divisional manager.

The left hand side variable \#segm of equation (18) is obtained from the question 'How many business segments do you have in the corporation?'.We followed the firms' own definition of a business segment. This implies that the level of aggregation of what constitutes a business segment varies across firms. In our sample the number of business segments varied between 0 (e.g for a holding company without a production unit) and 14 segments.

The right hand variables comp and worldcomp are subjective measures of competition as perceived by firms. They are obtained from the question 'How many competitors do you face on your local (Austrian or German) market and worldwide, respectively?' Firms tend to face many (269) or few (253) competitors (out of 630 firms) on local markets, while they face many (447) and few (112) competitors worldwide. No firm is a monopolist either locally or worldwide, while some firms did not find it profitable to enter the local market (76 firms) or the world market (48 firms). Since many of these firms are multi product firms, the subjective measure of competition is an average description over the firms' product range. The variable exports measures the trade exposure of firms and it is the ratio of firms' exports to firms' sales. The export ratio varies between zero and 285 percent. Due to intrafirm trade in intermediate goods across locations the firms' export ratio can exceed 100 percent. ${ }^{24}$ The variable link is obtained from the question 'What link exist between the business segments of your corporation - a technical link (input-output relation between the segments), a financial link (cash flow of one segment finances an other segment), an economic link (similar market knowledge)?' The variable link is ranked between 1 and 5 with 1 (perfect link) and 5 (no link). The link is perfect (1) when the firm consist of only one

\footnotetext{
${ }^{24}$ The new division of labor in the world economy has led to the emergence of countries as supertraders with export ratios exceeding 100 percent. A similar phenomenon can be observed at the level of global firms involved in the new international division of labor.
} 
business segment, 2 when the business segments in the firm have a technical, financial as well as economic link, 3 when only two out of the three links are present, 4 when only one out of the three links are present, and 5 when there is no link between business segments. The variable difqual indicates whether or not the products of the firm are differentiated in quality. Only 43 firms out of 683 responded that this is the case.

\subsection{Results}

We test the predictions for a cross section of 660 corporations in Austria and Germany. We first examine the relationship between the power allocation in firms, competition and market size. Table 4 presents ordinary least squares estimates of equation (17). In columns 1 to 6 we examine the effect of competition in the home market. In columns 1 to 3 we include the dummy competition and an interaction between competition and $\ln ($ cash $)$ to test for $\theta_{2}>0$ and $\theta_{3}>0$. We interact competition with $\ln ($ cash $)$ to see whether larger more profitable firms in larger markets change the effect of competition on the power allocation in firms. Alternatively, we interact competition with the country dummy nation in columns 4 to 6 to test for the same effect .

In contrast to what we expect, the estimated coefficients on competition itself are negative and significant (except for very competitive environments where very many tends to become insignificant and turns signs) suggesting that firms tend to centralize power with more competition compared to markets in which the firm faces no competitor (columns 1 to 3 ). We proceed by interacting competition with $\ln ($ cash). The estimated coefficients on the interaction of competition with $\ln ($ cash) are positive and significant (except for very many) suggesting that in larger more profitable markets a tougher competitive environment induces CEOs to place corporate decision power more decentrally at the divisional level. The estimated coefficients of about 0.065 imply that competition increases the average rank of corporate decisions in the firm by 0.065 . The average rank of corporate decisions of 2.81 (see Tables A1,A2 and A3) increases by about 0.065 to 2.875 .

A somewhat similar picture emerges when $\ln ($ cash $)$ is replaced by the country dummy nation in columns 4 to 6 . Now very many competitors has a significant negative coefficient, while many and few competitors turn sign and become insignificant. The estimated coefficients on the interaction term with nation are positive and mostly significant. They also tend to be larger compared with the interaction with $\ln ($ cash $)$. The estimated coefficients range between 0.168 and 1.107 increasing the average rank of corporate 
decisions between 2.978 and 3.917. This is an increase of up to one rank in the range of 1 to 5 indicating that competition has a quantitative important effect on firms' decision to decentralize power in the corporation.

In columns 7 to 12 we turn to competition in world markets. We replace localcompetition by worldcompetition to examine whether the relationship between competition and power in the firm changes when firms face competitors on world markets rather than on their home market. The results are shown in columns 7 to 9 for the interaction term of competition and $\ln ($ cash $)$ and in columns 10 to 12 for the interaction of competition and the country dummy nation. Competition alone turns insignificant in all specifications when firms face foreign competitors. However, the estimated coefficients on competition $* \ln ($ cash $)$ and on competition $*$ nation are positive and significantly different from zero at the $1 \%$ and $5 \%$ significance level in most specifications. They also tend to be larger compared to the estimated coefficients on localcompetition. The results suggest that in their decision over decentralizing power in the corporation, firms respond stronger to foreign compared to local competitors. Columns 4 to 6 and columns 10 to 12 support the claim of Prediction 1 that firms in larger countries with more competition will have more decentral corporate hierarchies. 


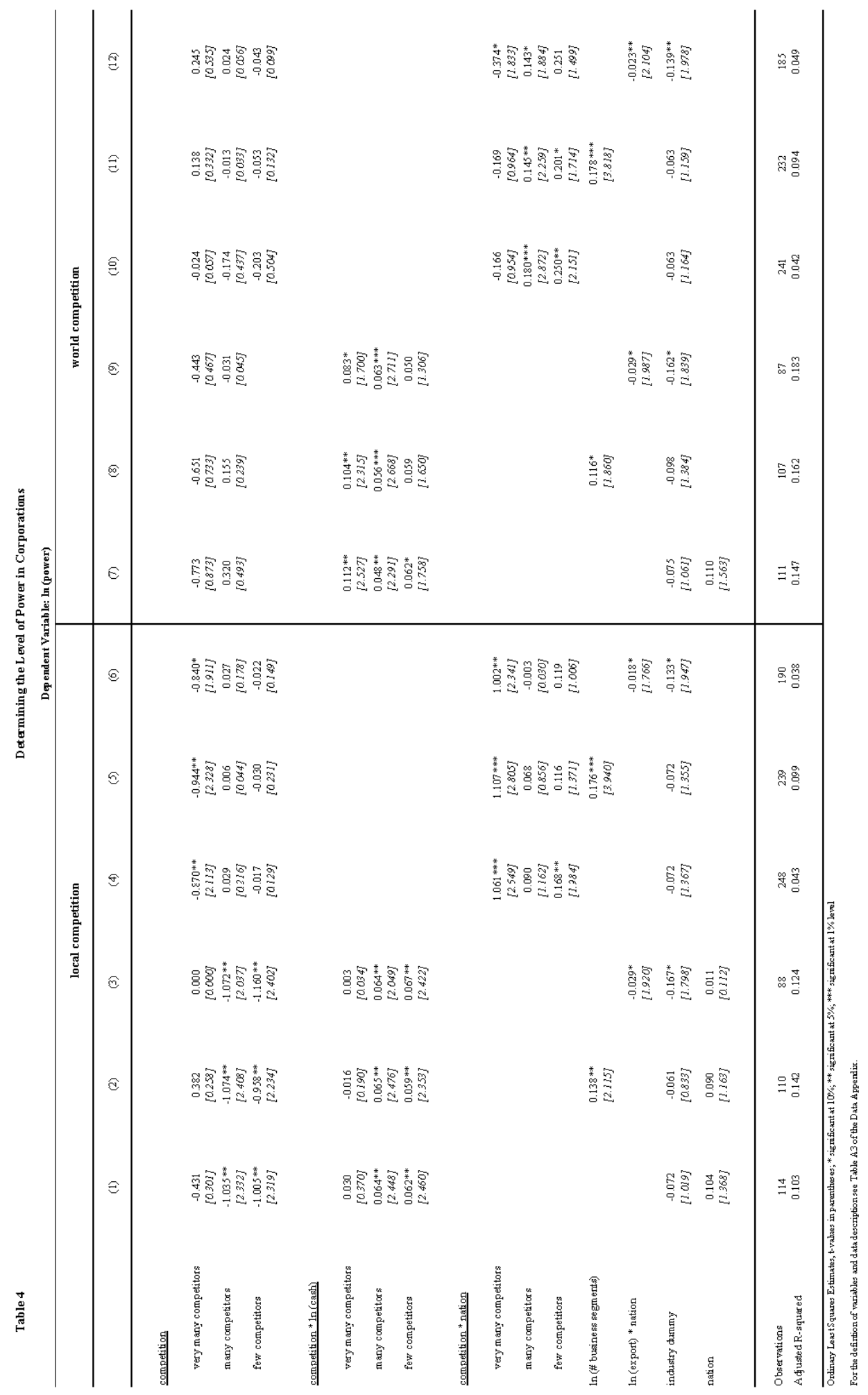


Next, we include $\ln (\text { export })_{i j} *$ nation to test Prediction 2 that $\theta_{4}<0$. The estimated coefficients are consistently negative and significant at conventional levels independent of specification. Finally, we include $\ln (\# \text { segments })_{i j}$ to test for $\theta_{5}>0$. We indeed find a positive and highly significant coefficient . We provide instrumental variables estimates of columns 2, 5, 8, and 11 when $\ln (\# \text { segments })_{i j}$ is included in the regressions in Table A4 of the Appendix to account for the fact that the conflict variable $\ln (\# \text { segments })_{i j}$ is endogenous in the model. We find similar, but somewhat weaker results when we instrument (\#segments) $)_{i j}$. with technical link. The latter is a good instrument for the former because both are positively correlated (firms tend to have more business segments when there is a technical link between the segments), while technical link appears not to be correlated with $(\text { power })_{i j}$.

Table 5 reports OLS estimates of equation (18) for a cross section of 660 firms in Austria and Germany. Columns 1 and 2 test for $\partial_{2}<0$. We find that when faced with more foreign competitors firms reduce the number of business segments by roughly 1 segment when competition is intense. The relationship weakens when competition becomes less tough and stops to be significant at conventional levels when the firm faces few competitors. In columns 1 and 2 we include the country dummy nation to see whether conflict in the firm is affected by the size of nations. Nation by itself turns out to be insignificant. We therefore interact nation with world competition to test for $\partial_{3}<0$. The results are shown in column 3. The estimated coefficients on world competition $*$ nation are negative and are now significant for all levels of competition, while world competition itself becomes insignificant

We proceed to include $\ln ($ power $)$ in the regression to test Prediction 4 that $\partial_{4}>0$ in columns 2 and 3 . $\ln$ (power) is positive and highly significant. We then interact $\ln ($ power) with nation (and alternatively with world competition) to test for the null $\partial_{5}=0$ in columns 5 and 4 . $\ln ($ power $) *$ nation and $\ln ($ power $) *$ world competition .are both highly significant at the 1 and 5 percent level rejecting the null of $\partial_{5}=0$. Nation is significant and turns negative when nation is interacted with $\ln$ (power) rather than with world competition.

We also include $\ln (\operatorname{link})$ to control for whether there is a link between the business segments in the firm. We assume that the stronger the link between business segments the more business segments can be kept without leading to the CEO's/owner's overload and loss of real power. The data confirm that this is indeed the case.

To check for robustness we provide instrumental variables estimates of 
columns 2 and 3 in Table A4 of the Appendix when $\ln$ (power) as an endogenous variable is included in the regressions. We use difquality as an instrument for power as both are positively correlated (decentralization of power appears to coincide with product differentiation) and difquality is little correlated with the number of business segments. The results become somewhat weaker, but remain valid. Overall, the data do not reject the claim of Predictions 3 and 4 that the power struggle in firms increases in larger more competitive markets and becomes less intense when firms are less hierarchically organized. 
Table 5

Determining the Level of Conflict in Corporations

Dependent Variable: In (\# business segments)

(1)
(3)

$\begin{array}{ll}-1.093^{*} & -0.971^{*} \\ {[1.789]} & {[1.936]} \\ -0.992 & -0.833^{*} \\ {[1.641]} & {[1.701]} \\ -0.984 & -0.766 \\ {[1.621]} & {[1.553]}\end{array}$

(4)

$\begin{array}{cccc} & -1.136^{* * *} & -0.904^{*} & -0.740 \\ & {[2.008]} & {[1.800]} & {[1.252]} \\ 0.122 & -1.187^{* * *} & -0.825^{*} & -1.078^{* *} \\ {[0709]} & {[2.372]} & {[1.683]} & {[2.161]} \\ 0.188 & -0.889^{*} & -0.774 & -0.829 \\ {[1.003]} & {[1.707]} & {[1.570]} & {[1.602]}\end{array}$

(5)

world competition

very many competitor

many competitors

few competitors

world competition*nation

very many competitors

many competitors

few competitors

world competition * $\ln$ (power)

very many competitors

many competitors

few competitors

ln (link)

In (power)

$\ln ($ power) * nation

incustry dummy

nation

$$
\begin{aligned}
& 0.114^{* *} \\
& {[2.266]}
\end{aligned}
$$

-0.063
$[1.247]$

$$
\frac{0.603^{* * * * *}}{[7.034]}
$$$$
\begin{aligned}
& 0.602^{* * * * * *} \\
& {[6.979]}
\end{aligned}
$$$$
-0.984 *
$$$$
-0.954^{*}
$$$$
\begin{gathered}
-0.9227 \\
-0.950^{*}
\end{gathered}
$$$$
\begin{aligned}
& -0.950^{*} \\
& {[1.770]}
\end{aligned}
$$

nation

Observations
Adjusted R-squar

587

$0.260^{k-k * k}$

$$
\text { [3.210] }
$$

$0.259^{\text {k-k k k }}$

R-squared

0.01

229

0.244

229

229

229

229

Ordinary Least Squares Estimates, $\mathrm{t}$-values in parentheses; * significant at $10 \% ; * *$ significant at $5 \% ; * * *$ significant at $1 \%$ level For the definition of variables and data description see Table A3 of the Data Appendix.

\section{Conclusion}

Can differences in countries exposure to trade account for the observed differences in corporate organization across countries and firms? Can an increased integration into the world economy explain the trend towards less hierarchical 
organizations in rich countries? We have developed a model that combines the Krugman cum Melitz and Ottaviano model of trade with the Aghion and Tirole theory of the firm to answer these questions raised in the introduction. Our model traces a link between the size of nations, competition and corporate organization which can account for the facts identified in the introduction. We derive predictions from our model which we test with unique survey data of global corporations for two countries.

\section{References}

[1] Aghion, P. and J. Tirole. 1997. Formal and Real Authority in Organizations. Journal of Political Economy. 105 (1). pp. 1-29.

[2] Bolton, P.and D Scharfstein. 1998. Corporate Finance, the Theory of the Firm, and Organizations. Journal of Economic Perspectives. 12 (4). pp. 95-114.

[3] Dixit, A. and J. Stiglitz .1977. Monopolistic Competition and Optimum Product Diversity.American Economic Review. 67 (3). pp. 297-308.

[4] Helpman, E. 2006. Trade, FDI, and the Organization of Firms. Centre for Economic Policy Research. CEPR Discussion Paper No. 5589. London.

[5] Helpman, E. and P. Krugman. 1985. Market Structure and Foreign Trade. MIT Press. Cambridge.

[6] Holmstrom, B. and St. N. Kaplan. 2001. Corporate Governance and Merger Activity in the United States. Journal of Economic Perspectives. 15 (2). pp. 121-144.

[7] Krugman, P. 1979. Increasing Returns, Monopolistic Competition, and International Trade. Journal of International Economics 9, 469-479.

[8] Krugman, P. 1980. Scale Economies, Product Differentiation, and the Pattern of Trade. American Economic Review.70.950-959.

[9] Marin, D. 2006. A New International Division of Labor in Europe: Outsourcing and Offshoring to Eastern Europe. Journal of the European Economic Association, Papers and Proceedings, pp. 612-623.

[10] Marin, D. and T. Verdier. 2003a. Globalization and the 'New Enterprise'. Journal of the European Economic Association. Papers and Proceedings. 
[11] Marin, D. and T. Verdier. 2003b. Globalization and the Empowerment of Talent. Centre for Economic Policy Reseach. CEPR Discussion Paper No. 4129, London.

[12] Marin, D. and T. Verdier 2006. Competing in Organizations: Firm Heterogeneity and the New Comparative Advantage, University of Munich and Paris School of Economics, Mimeo.

[13] Marin, D. and T. Verdier. 2007. Power Inside the Firm and the Market: A General Equilibrium Approach. Journal of the European Economic Association, forthcoming.

[14] Melitz, M. 2003. The Impact of Trade on Aggregate Industry Productivity and Intra-Industry Reallocations. Econometrica 71 (6). pp. 16951726 .

[15] Melitz, M. and G. Ottaviano. 2003. Market Size, Trade and Productivity. Harvard University, Department of Economics. mimeo

[16] Osterman, P. 1996. Broken Ladders: Managerial Careers in the New Economy. New York: Oxford University Press.

[17] Rajan, R. G., H. Servaes and L. Zingales. The Cost of Diversity: Diversification Discount and Inefficient Investment. Journal of Finance 55. pp. $35-80$.

[18] Rajan, R. G. and J. Wulf. 2003. The Flattening Firm: Evidence from Panel Data on the Changing Nature of Corporate Hierarchies. University of Chicago. Mimeo.

[19] Spencer, Barbara J. 2005. International Outsourcing and Incomplete Contracts, Canadian Journal of Economics 38, pp 1107-1135.

[20] Williamsom, O.E. 1975. Markets and Hierachies. Analysis and Antitrust Implications. New York/London. 


\section{Appendix A: The Data}

Table A1 Decisions Ranked by Level of Corporate Hierarchy

\begin{tabular}{lc}
\multicolumn{2}{c}{ Austrian Corporations } \\
\hline \multicolumn{2}{c}{ mean } \\
\hline 1. decision over acquisitions & 1.31 \\
2. financial decisions & 1.76 \\
3. new strategy & 1.86 \\
4. transfer prices & 2.25 \\
5. hiring more than 10\% of current personnel & 2.42 \\
6. R\&D expenditures & 2.44 \\
7. budget & 2.63 \\
8. introduction of new products & 2.76 \\
9. change of supplier & 3.04 \\
10. moderate wage increase & 3.12 \\
11. decision over product price & 3.37 \\
12. hiring two workers & 3.44 \\
13. hiring a secretary & 3.95 \\
\hline
\end{tabular}


Table A2 Decisions Ranked by Level of Corporate Hierarchy

\begin{tabular}{|c|c|}
\hline \multicolumn{2}{|l|}{ German Corporations } \\
\hline & mean \\
\hline 1. decision over acquisitions & 1.35 \\
\hline 2. financial decisions & 1.91 \\
\hline 3. new strategy & 2.01 \\
\hline 4. find acquisition & 2.58 \\
\hline 5. transfer prices & 2.58 \\
\hline 6. hiring more than $10 \%$ of current personnel & 2.66 \\
\hline 7. $R \& D$ expenditures & 2.67 \\
\hline 8. introduction of new products & 2.68 \\
\hline 9. budget & 2.74 \\
\hline 10. change of supplier & 3.31 \\
\hline 11. decision over product price & 3.56 \\
\hline 12. price increase of product & 3.63 \\
\hline 13. moderate wage increase & 3.76 \\
\hline 14. hiring two workers & 4.04 \\
\hline 15. firing of personnel & 4.28 \\
\hline 16. hiring a secretary & 4.32 \\
\hline
\end{tabular}


Table A3

Definition of Variables and Sample Statistics

\begin{tabular}{|c|c|c|c|c|c|c|}
\hline Variable & $\begin{array}{c}\text { obser- } \\
\text { vations }\end{array}$ & description & mean & minimum & maximum & stand. dev. \\
\hline power & 256 & $\begin{array}{l}16 \text { corporate decision (Germany) and } 13 \text { corporate } \\
\text { decision (Austria) ranked between } 1 \text { and } 5 \text { with } 1 \text { as the } \\
\text { decision taken by the CEO (central decision) and } 5 \text { as } \\
\text { the decision taken at the divisional level (decentral } \\
\text { decision). The numbers are means over the } 16 \text { (13) } \\
\text { decisions. A firm with a mean at } 1 \text { is centralized and a } \\
\text { firm with a mean of } 5 \text { is decentralized. Corporate } \\
\text { decisions include: decision over acquisitions, financial } \\
\text { decisions, new strategy, finding acquisitions, transfer } \\
\text { prices, introduction of new products, R\&D } \\
\text { expenditures, budget, hiring more than } 10 \% \text { of current } \\
\text { personnel, hiring two workers, change of supplier, price } \\
\text { increase of product, decision over product price, } \\
\text { moderate wage increase, firing of personnel, hiring a } \\
\text { secretary. For the ranking of these decisions see Tables } \\
\text { A1 and A2. }\end{array}$ & 2.81 & 1.00 & 5.00 & 0.89 \\
\hline cash flow & 322 & firms' cash flow in million EUR & 51 & -66 & 5,930 & 360 \\
\hline local competition & & local competition as perceived by firms & & & & \\
\hline $\begin{array}{l}\text { very many } \\
\text { competitors }\end{array}$ & 630 & $\begin{array}{l}\text { dummy variable equal to } 1 \text { and } 0 \text { otherwise when firm } \\
\text { does not enter the market }\end{array}$ & & \multicolumn{2}{|c|}{$\mathrm{D}=1,76$ observations } & \\
\hline many competitors & 630 & $\begin{array}{l}\text { dummy variable equal to } 1 \text { and } 0 \text { otherwise when firm } \\
\text { faces many competitors }\end{array}$ & & \multicolumn{2}{|c|}{$\mathrm{D}=1,269$ observations } & \\
\hline few competitors & 630 & $\begin{array}{l}\text { dummy variable equal to } 1 \text { and } 0 \text { otherwise when firm } \\
\text { faces few competitors }\end{array}$ & & \multicolumn{2}{|c|}{$\mathrm{D}=1,253$ observations } & \\
\hline no competitors & 608 & $\begin{array}{l}\text { dummy variable equal to } 1 \text { and } 0 \text { otherwise when firm } \\
\text { faces no competitors }\end{array}$ & & \multicolumn{2}{|c|}{$\mathrm{D}=1,32$ observations } & \\
\hline world competition & & world competition as perceived by firms & & & & \\
\hline $\begin{array}{l}\text { very many } \\
\text { competitors }\end{array}$ & 608 & $\begin{array}{l}\text { dummy variable equal to } 1 \text { and } 0 \text { otherwise when firm } \\
\text { does not enter the market }\end{array}$ & & \multicolumn{2}{|c|}{$\mathrm{D}=1,48$ observations } & \\
\hline many competitors & 608 & $\begin{array}{l}\text { dummy variable equal to } 1 \text { and } 0 \text { otherwise when firm } \\
\text { faces many foreign competitors }\end{array}$ & & \multicolumn{2}{|c|}{$\mathrm{D}=1,447$ observations } & \\
\hline few competitors & 608 & $\begin{array}{l}\text { dummy variable equal to } 1 \text { and } 0 \text { otherwise when firm } \\
\text { faces few foreign competitors }\end{array}$ & & \multicolumn{2}{|c|}{$\mathrm{D}=1,112$ observations } & \\
\hline no competitors & 630 & $\begin{array}{l}\text { dummy variable equal to } 1 \text { and } 0 \text { otherwise when firm } \\
\text { faces no foreign competitors }\end{array}$ & & \multicolumn{2}{|c|}{$\mathrm{D}=1,1$ observation } & \\
\hline export & 502 & firms' exports in percent of firms' sales & 35.53 & 0.00 & 285 & 80.02 \\
\hline $\begin{array}{l}\text { \# business } \\
\text { segments }\end{array}$ & 638 & number of business segments in the firm & 3.29 & 0 & 14 & 1.96 \\
\hline link & 625 & $\begin{array}{l}\text { links (technical, financial, economic) between business } \\
\text { segments ranked between } 1 \text { (perfect link) and } 5 \text { (no } \\
\text { link), } 1=\text { one segment, } 2=\text { all three links are present, } 3= \\
\text { two links are present, } 4=\text { one link is present, } 5=\text { no link } \\
\text { is present }\end{array}$ & 2.51 & 1 & 5 & 0.95 \\
\hline nation & 665 & $\begin{array}{l}\text { dummy variable equal to } 1 \text { if the country is Germany } \\
\text { and } 0 \text { if it is Austria }\end{array}$ & & \multicolumn{2}{|c|}{$\mathrm{D}=1,457$ observations } & \\
\hline technical link & 527 & $\begin{array}{l}\text { dummy variable equal to } 1 \text { and } 0 \text { otherwise, if there is a } \\
\text { technical link between business segments }\end{array}$ & & \multicolumn{2}{|c|}{$\mathrm{D}=1,406$ observations } & \\
\hline difquality & 638 & $\begin{array}{l}\text { dummy variable equal to } 1 \text { and } 0 \text { otherwise, if the firm's } \\
\text { product is differentiated in quality }\end{array}$ & & \multicolumn{2}{|c|}{$\mathrm{D}=1,43$ observations } & \\
\hline industry dummy & 665 & $\begin{array}{l}\text { dummy variable equal to } 1 \text { if the sector is services and } \\
0 \text { if it is industry }\end{array}$ & & \multicolumn{2}{|c|}{$\mathrm{D}=1,286$ observations } & \\
\hline
\end{tabular}




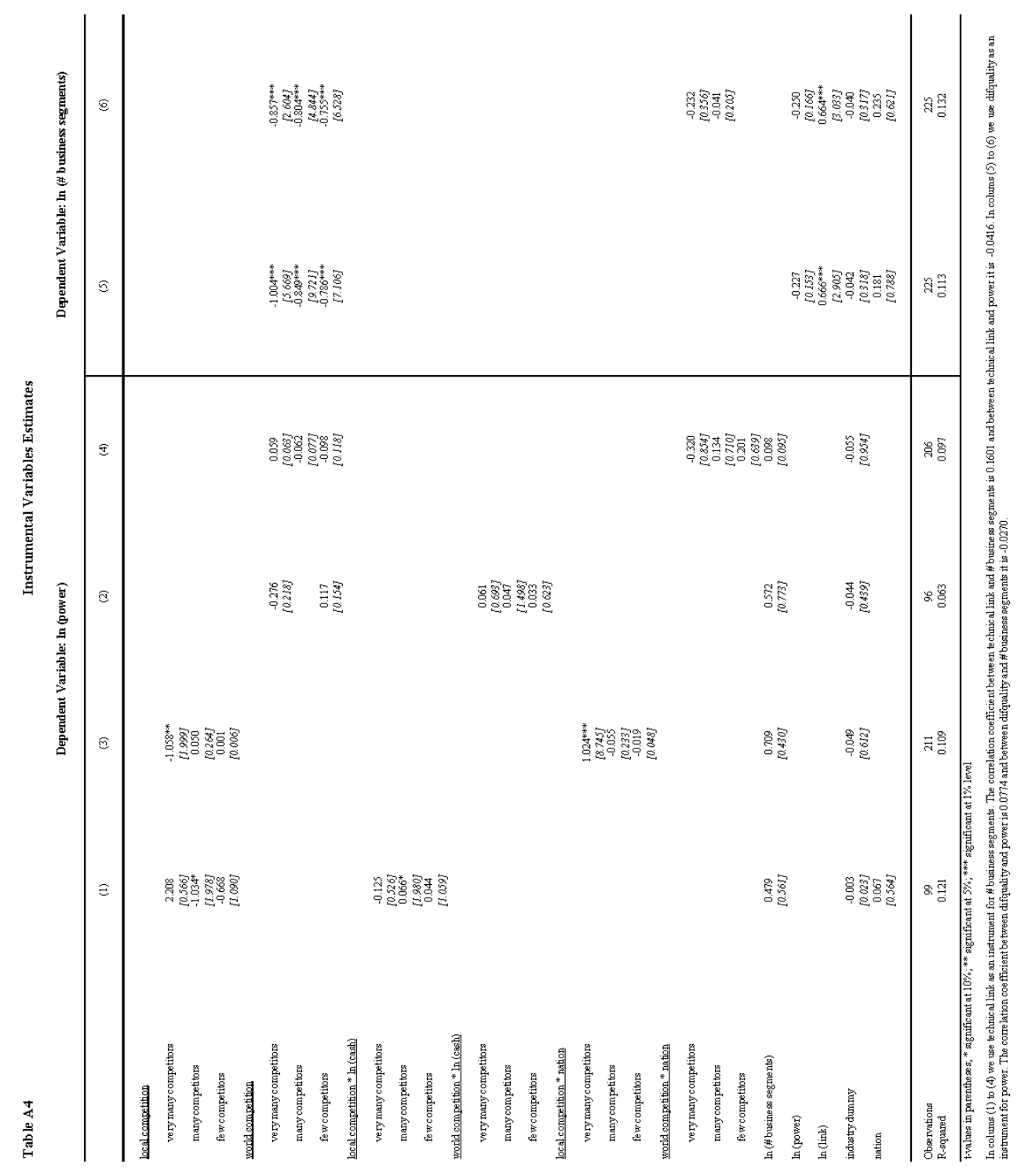




\section{Appendix B}

- Proof of Properties of $\widehat{B}(\alpha)$. Available from the authors upon request

- Proof of Existence of $\left(B^{e}, \alpha^{e}\right)$ equilibrium. Available from the authors upon request. 